\title{
O EFEITO DIRECTO DO DIREITO DA UNIÃO EUROPEIA: UMA VISÃO CONDENSADA DO ENQUADRAMENTO DUMA PREEMINENTE CRIAÇÃO JURISPRUDENCIAL
}

\author{
THE DIRECT EFFECT OF THE LAW OF THE EUROPEAN UNION: \\ A CONDENSED PERSPECTIVE OF THE FRAMEWORK OF AN \\ IMPORTANT CASE LAW CREATION
}

\begin{abstract}
Abel Laureano*
RESUMO: $O$ efeito directo de certas normas não consta expressamente de qualquer preceito dos Tratados da União Europeia: na génese da sua descoberta está uma elaboração jurisprudencial levada a cabo pelo Tribunal de Justiça. Pensamos que, com o qualificativo efeito directo, se deve rotular a característica, de algumas disposições do Direito da União Europeia, de serem base válida para atribuir aos particulares direitos que estes podem invocar perante as autoridades nacionais. Próxima, mas devendo distinguir-se daquele, é a aplicabilidade directa em sentido restrito, característica das normas da União que entram só por si a fazer parte da Ordem Jurídica dos Estados-membros (ou seja, independentemente de mediação destes), não tendo contudo efeito directo - mas, quando se alude ao princípio da aplicabilidade directa, sem mais, deve entender-se, em nossa opinião, que a expressão "aplicabilidade directa" corresponde à ideia de aplicabilidade directa em sentido amplo; e esta resulta, em nosso entendimento, do somatório da aplicabilidade directa em sentido restrito com o efeito directo. A entrada em vigor do recente Tratado de Lisboa não parece implicar assinaláveis perspectivas de mudança das grandes linhas conceituais anteriores.
\end{abstract}

PALAVRAS-CHAVE: Efeito directo. Aplicabilidade directa. Direito da União Europeia.

ABSTRACT: The direct effect of some rules does not appear explicitly in any provision of the Treaties on the European Union: the genesis of his discovery is an elaboration of case law, as result of a legal construction carried out by the Court of Justice. We think that the expression direct effect should label the attribute, of certain provisions of European Union Law, of being a valid basis to confer, upon individuals, rights which are enforceable before national authorities. Next to that characteristic, but worth a clear distinction, is what may be called as direct applicability in the strict sense, which characterizes those Union rules that become automatically part of the legal order of the Member States (ie, without the States' mediation), yet not having direct effect - but, when reference is made to the principle of direct applicability, without saying more, it should be understood, in our opinion, that the expression "direct applicability" refers to the idea of direct applicability in a broad sense, which, in our view, is the result of the sum of the direct applicability in the strict sense plus the direct effect. The recent entry into force of the Lisbon Treaty doesn't seem to imply remarkable prospects for change of the major previous framework.

KEYWORDS: Direct effect. Direct applicability. European Union Law.

* Docente da Universidade do Porto. Mestre em Direito (Integração Europeia) pela Universidade de Coimbra. Diploma de Estudios Aprofundizados (D.E.A.) pela Universidad de Santiago de Compostela (Espanha). Diploma em Estudos Europeus (D.E.E.) pela Universidade de Lisboa. Pós-graduado em Estudos Europeus pela Universidade de Lisboa. Licenciado em Direito pela Universidade de Lisboa. E-mail: alaureano1@gmail.com. 
Sucede em todos os ramos do Direito, da Ordem Jurídica, que a exacta perspectivação do conteúdo dos respectivos princípios gerais tem inquestionável e inestimável valor enquanto explicitação (ou descoberta) do alcance normativo destes; assim se põem a claro os fundamentais comandos jurídicos disciplinantes do respectivo Sistema Jurídico, sem cujo total conhecimento e aplicação se atraiçoaria afinal tal Sistema.

Para além das necessidades assim referidas, e como complemento delas, importa também articular dogmaticamente os princípios gerais entre si. Isto porque, como parece actualmente entendimento pacífico, a Ciência Jurídica tem um valor teórico a se, ainda quando se não vejam de imediato as repercussões práticas da edificação científico-jurídica.

Este trabalho localiza-se no âmbito do parágrafo acabado de escrever. É um trabalho onde iremos debruçar-nos sobre o que tem sido maioritariamente rotulado por duas expressões: aplicabilidade directa e efeito directo ${ }^{2}$. Isto para tentarmos apreender o que tais expressões traduzem; $e$, no caso de deverem corresponder a conteúdos distintos, qual a articulação entre estes.

Mas trata-se, afinal, duma questão conceptual ou terminológica? Entendemos por bem lembrar antes de mais, na verdade, o facto de haver, a nível doutrinário, quem dalgum modo ignore esta problemática, olhando-a essencialmente dum prisma que a reconduz, expressa ou implicitamente, a uma questão terminológica ${ }^{3}$. Ora cremos que, na Ciência Jurídica, a terminologia tem um papel nunca despiciendo,

1 Abreviaturas: Ac.: Acórdão; $c .:$ considerando(s) (fundamentos do acórdão ou despacho); CE: Comunidade Europeia; CEE: Comunidade Económica Europeia; Col.: Colectânea da Jurisprudência do Tribunal; a partir de 1990, Colectânea da Jurisprudência do Tribunal de Justiça e do Tribunal de Primeira Instância (versão portuguesa); disposit.: dispositivo (parte decisória do acórdão ou despacho); par.: parágrafo; Rec.: Recueil de la jurisprudence de la Cour (versão francesa); TFUE: Tratado sobre o Funcionamento da União Europeia; TJCE: Tribunal de Justiça das Comunidades Europeias; TJUE: Tribunal de Justiça da União Europeia; Tratado CE: Tratado institutivo da Comunidade Europeia; Tratado CEE: Tratado institutivo da Comunidade Económica Europeia.

2 É tão importante a temática do efeito directo, que já se comentou, mesmo relativamente a um dos seus aspectos dogmáticos, tratar-se duma "questão-chave" (TORRES CAZORLA, María Isabel. La normativa comunitaria en materia turística y su aplicación por el Tribunal de Justicia Comunitario. Revista Andaluza de Derecho del Turismo. jun. 2010, n. 4, p. 11-46, p. 19).

2 Cremos ser o caso, p. ex., de MENGOZZI, Paolo. Istituzioni di diritto comunitario e dell'Unione europea: Padova, CEDAM, 2003, tendo em conta o modo como se pronuncia, particularmente, na p. 171; ou, mais recentemente, de Sandulli, Irene. La responsabilità dello Stato-Amministrazione per violazione del diritto comunitario, fra istanze di certezza giuridica e tutela del principio dell'affidamento. Università degli studi di Roma 'Tor Vergata', Facolta' di Giurisprudenza, dottorato di ricerca in diritto pubblico, XXI Ciclo, 2008/2009, considerando designadamente o pensamento consignado nas páginas 11 a 14. Disponível em: <http://dspace. uniroma2.it/dspace/bitstream/2108/1032/1/Tesi+Irene+Sandulli.pdf>. Acesso em: 27 maio 2013. 
e que portanto o ponto teria sempre dignidade para análise. Mas pensamos que o tema proposto vai mais além; ou seja, para nós não se trata de uma questão de termos, mas sim de conceitos: importa definir em que julgamos consistir o conteúdo certo de cada uma das expressões (aplicabilidade directa e efeito directo), sendo esse um verdadeiro e próprio problema em si. Que se questione, depois, dos termos mais próprios a empregar para designar tais realidades, é problema diferente, do qual não curaremos aqui.

O esquema expositivo que seguiremos é muito simples, dividindo-se em dois tempos. Num primeiro tempo, vamos apresentar o material jurídico objecto de análise (mais pormenorizadamente, normas expressas do Direito Comunitário Originário e pronunciamentos da jurisprudência comunitária). Vem depois, como conteúdo específico deste trabalho, a apresentação e justificação da nossa posição, ou melhor, do entendimento que sufragamos relativamente aos contornos do efeito directo, no cotejo com a aplicabilidade directa.

\section{O TEXTO DOS TRATADOS E A JURISPRUDÊNCIA COMUNITÁRIA}

I. Com relevância para o tema que nos ocupa, surge naturalmente em primeiro lugar o Direito Comunitário Originário. Por ele começamos e a ele nos cingiremos, de resto, pelo que toca aos elementos literais decisivos, já que o Direito Comunitário Derivado nada de relevante acrescenta na matéria.

Antes do Tratado da União Europeia, a única disposição expressamente invocável em sede desta temática era o artigo $189^{\circ}$ do Tratado CEE.

Após aquele Tratado, um novo preceito era chamável à colação: o artigo $108^{\circ}$-A, do Tratado CE, que estatuía sobre actos do Banco Central Europeu. Este último artigo, porém, nada de novo trazia quanto ao delineamento da matéria do nosso tema (o normativo consagrava, no seu $n^{\circ} 2$, ipsis verbis, as soluções que já decorriam dos parágrafos 2 e 4, do artigo $189^{\circ}$, do Tratado CEE). O que levava a focalizar a atenção no artigo $189^{\circ}$, do Tratado $\mathrm{CE}$; sendo que este, relativamente aos parágrafos que agora pontualmente nos interessam, não viu o antigo texto do Tratado CEE ser modificado em Maastricht ${ }^{4}$.

Estes últimos textos jurídicos jamais sofreram aliás qualquer alteração de substância com as revisões sucessivamente operadas pelos Tratados de Amesterdão e de Nice, por força dos quais passaram a integrar o artigo $249^{\circ}$, do Tratado CE, mantendo o teor original do Tratado de 1957.

4 Dizia o par. 2, do artigo $189^{\circ}$, na versão do Tratado de Maastricht: "O regulamento tem carácter geral. É obrigatório em todos os seus elementos e directamente aplicável em todos os Estados-membros." E o par. 4, por seu turno, dispunha: "A decisão é obrigatória em todos os seus elementos para os destinatários que designar". 
E, dentro da mesma linha de continuidade, os correspondentes preceitos basilares do vigente Tratado sobre o Funcionamento da União Europeia (conformadores do actual figurino da União Europeia, constante do Tratado de Lisboa) estabelecem, respectivamente: "O regulamento tem carácter geral. É obrigatório em todos os seus elementos e directamente aplicável em todos os Estados-membros." (parágrafo 2, do artigo 288, do TFUE). “A decisão é obrigatória em todos os seus elementos. Quando designa destinatários, só é obrigatória para estes." (parágrafo 4, do artigo $288^{\circ}$, do TFUE). Tomando como ponto de partida esta específica base literal, a entrada em vigor do Tratado de Lisboa não parece pois implicar assinaláveis perspectivas de mudança das grandes linhas conceituais vislumbradas pelo Tribunal de Justiça. Mas, como salienta alguma doutrina, não se pode excluir radicalmente a hipótese duma qualquer mudança, até porque o Tratado de Lisboa aponta no sentido dalgum reforço da integração europeia ${ }^{5}$.

II. Transcrever um elenco de toda a jurisprudência comunitária alusiva à problemática em apreço seria nefasto, por subverter a dimensão e o espírito deste trabalho, que se pretende sintético. Temos assim por preferível adiantar um balanço, ilustrando-o com exemplos seleccionados.

A nosso ver, a posição assumida pelo juiz comunitário não se afigura linear. Se a observação de bastantes acórdãos parece inclinar num dado sentido, outros vão, ao menos aparentemente, em sentido algo diverso. Globalmente, o panorama carece pois de alguma nitidez.

Devem fazer-se, contudo, duas observações liminares. Por um lado, nunca se deve esquecer que o Tribunal de Justiça se não encontra vinculado pela regra do precedente, embora se atenha com bastante frequência à linha dos seus pronunciamentos anteriores ${ }^{6}$. Por outro lado, não falta quem sustente que, por via de regra, o Tribunal de Justiça emprega as locuções efeito directo e aplicabilidade

5 Assim, WOHLFAHRT, Christian. Veränderungen des Lissabon-Vertrages im Hinblick auf die Doktrin der unmittelbaren Wirkung. Zeitschrift für ausländisches öffentliches Recht und Völkerrecht, 2010 , v. 70, p. 523-545, p. 544-545. Disponível em: <http://www.zaoerv.de/70_2010/70_2010_3_a_523_546.pdf>. Acesso em: 26 maio 2013.

6 Sobre o assunto, vejam-se os judiciosos comentários de CraIG, Paul. The legal effect of directives: policy, rules and exceptions. University of Oxford Legal Research Paper Series, aug. 2009, n. 24, p. 349377, p. 377. Disponível em: <http://papers.ssrn.com/sol3/papers.cfm?abstract_id=1433782>. Acesso em: 24 maio 2013. Claro está que esta circunstância em nada colide, dado situar-se num plano distinto, com a óbvia (embora por vezes secundarizada) asserção de que qualquer decisão judicial "deve ser avaliada [...] no contexto histórico e político em que foi adoptada" (PACE, Alessandro. La sentenza Granital, ventitrè anni dopo. Studi sull'integrazione europea, 2007, v. 2, fasc. 3, p. 451-467, p. 460). 
directa indiscriminadamente, tendo de inferir-se, do conteúdo de cada decisão, os respectivos sentidos ${ }^{7}$.

III. Antes de mais, e pelo que toca à expressão efeito directo, o Tribunal de Justiça parece privilegiá-la exclusivamente, em significativos acórdãos, para rotular a característica, de certas disposições do Direito Comunitário, de serem base válida para atribuir aos particulares direitos que estes podem invocar perante os órgãos jurisdicionais nacionais ${ }^{8}$ (naturalmente a título de instâncias de último recurso em caso de conflitualidade jurídica ${ }^{9}$, sem discriminações subjacentes $^{10}$, e em

7 Assim, LORENZON, Sara. Teoria degli effetti diretti e applicazione del diritto: l'efficacia delle norme self-executing nell'nterpretazione della corte di giustizia e del giudice interno. Tese de doutoramento, Università degli Studi di Ferrara. Annali online: Pubblicazioni dello IUSS, 2008, v. 2, n. 1, p. I. Disponível em: $<$ http://annali.unife.it/iuss/article/download/328/281>. Acesso em: 24 maio 2013. Numa posição menos contundente, referindo-se à existência de "irregularidades" terminológicas do Tribunal de Justiça, RoDER, Thomas. Die horizontale Wirkung nicht umgesetzter EG-Richtlinien. Dissertation zur Erlangung des akademischen Grades doctor juris (Dr. iur.) vorgelegt dem Fakultätsrat der Rechtswissenschaftlichen Fakultät der FriedrichSchiller-Universität Jena, 2007, p. 1. Disponível em: <http:/www.db-thueringen.de/servlets/DerivateServlet/ Derivate-13306/Dissertation\%20Thomas\%20Roder.pdf>. Acesso em: 26 maio 2013.

${ }^{8}$ Quanto à ideia central de os preceitos dotados de efeito directo poderem ser invocados nos órgãos jurisdicionais nacionais (designadamente para afastar a aplicação das regras de Direito Interno contrárias), vejam-se, de entre as manifestações mais actuais, o Ac. TJUE 15 de novembro de 2011, Murat Dereci e o. / Bundesministerium für Inneres, C-256/11, c. n. 87. Disponível em: <http://curia.europa.eu/juris/ document/document.jsf ?docid $=114222 \& \operatorname{mode}=\mathrm{req} \&$ pageIndex $=1 \& \mathrm{dir}=\&$ occ $=$ first $\& \mathrm{part}$ $=1 \&$ text $=\% 2522$ efeito $\% 2$ Bdirecto $\% 2522 \&$ doclang=PT\&cid=190338\#ctxl>. Acesso em: 11 jun. 2013; o Ac. TJUE 10 de novembro de 2011, Commissioners for Her Majesty's Revenue and Customs / The Rank Group plc, C-259/10 e C-260/10, c. n. 69. Disponível em: <http://curia.europa.eu/juris/document/document.jsf? docid $=113588 \&$ mode $=$ req \& pageIndex $=1 \&$ dir $=$ \&occ $=$ first $\&$ part $=1 \&$ text $=\% 2522$ efeito $\% 2$ Bdirecto \%2522\&doclang=PT\&cid=190338\#ctxl>. Acesso em: 11 jun. 2013; ou o Ac. TJUE 25 de novembro de 2010 , Günter Fuß/ Stadt Halle, C-429/09, c.n. 35. Disponível em:<http://curia.europa.eu/juris/document/document. jsf ?doclang $=$ PT\&text $=\% 2522$ efeito $\% 2$ Bdirecto $\% 2522 \&$ pageIndex $=3 \&$ docid $=79740 \&$ mode $=$ req $\&$ part $=$ $1 \&$ occ $=$ first \&dir $=\& \operatorname{cid}=206561 \#$ ctx1 $>$. Acesso em: 11 jun. 2013.

9 O Tribunal de Justiça não deixa de insistir, mesmo na actualidade, na asserção de que um preceito dotado de efeito directo se impõe a "todas as autoridades dos Estados-membros, isto é, não só aos tribunais nacionais mas também a todos os órgãos da administração, incluindo as entidades descentralizadas, tais como os Länder, as cidades ou os municípios" (Ac. TJUE 14 de outubro de 2010, Günter Fuß / Stadt Halle, C-243/09, c. n. 61. Disponível em: <http://curia.europa.eu/juris/document/document.jsf?docid $=82939 \&$ mode $=$ req\&pageIndex $=3 \&$ dir $=$ \&occ $=$ first $\&$ part $=1 \&$ text $=\% 2522$ efeito $\% 2 \mathrm{Bdirecto} \% 2522 \&$ doclang=PT\&cid=206561\#ctx1>). Acesso em: 11 jun. 2013). Numa formulação ainda mais ampla (incluindo os casos em que o Estado aja como empregador), Ac. TJUE 10 de maio de 2011, Jürgen Römer / Freie und Hansestadt Hamburg, C-147/08, c. n. 55, Disponível em: <http://curia.europa.eu/juris/document/document.jsf ?docid=80921\&mode $=$ req\&pageIndex $=3 \&$ dir $=\& o c c=$ first $\&$ part $=1 \&$ text $=\% 2522$ directamente \%2Baplic\%25C3\%25Alvel\%2522\&doclang=PT\&cid=314174\#ctx1>. Acesso em: 12 jun. 2013.

${ }^{10}$ Numa jurisprudência recentemente reafirmada, "não havendo regulamentação comunitária na matéria, cabe à ordem jurídica interna de cada Estado-membro designar os órgãos jurisdicionais compe- 
homenagem ao princípio do primado do Direito Comunitário $\left.{ }^{11}\right)$.

$E$ o efeito directo tem lugar, basicamente, desde que tais disposições sejam incondicionais $^{12}$ e suficientemente claras e precisas ${ }^{13}$, requisitos estes que têm sido repetidamente afirmados pelo Tribunal de Justiça ${ }^{14}$.

tentes e regular as modalidades processuais dos recursos destinados a garantir a salvaguarda dos direitos atribuídos aos particulares por força do efeito directo do direito comunitário, contanto que essas modalidades não sejam menos favoráveis do que as que regulam os recursos similares de natureza interna (princípio da equivalência) e não tornem impossível, na prática, ou excessivamente difícil o exercício dos direitos conferidos pela ordem jurídica comunitária (princípio da efectividade)" (Ac. TJUE 28 de janeiro de 2010, Belgische Staat / Direct Parcel Distribution Belgium NV, C-264/08, c. n. 33. Disponível em: <http://curia. europa.eu/juris/document/document.jsf ?docid $=72516 \&$ mode $=$ req \&pageIndex $=5 \&$ dir $=\&$ occ $=$ first $\&$ part $=1 \&$ text=\%2522efeito\%2Bdirecto\%2522\&doclang=PT\&cid=214756\#ctxl>). Acesso em: 11 jun. 2013.

11 Para uma referência actual à ligação entre o efeito directo e o primado, p. ex.: Ac. TJCE 8 de setembro de 2010, Winner Wetten GmbH / Bürgermeisterin der Stadt Bergheim, C-409/06, c. n 60. Disponível em: <http:// curia.europa.eu/juris/document/document.jsf $?$ docid $=80771 \&$ mode $=$ req\&pageIndex $=8 \& d i r=\& o c c=$ first \&part=1\&text=\%2522efeito\%2Bdirecto\%2522\&doclang=PT\&cid=234323\#ctx1>. Acesso em: 11 jun. 2013.

${ }_{12} \mathrm{Na}$ jurisprudência presente, pode ver-se o Ac. TJUE 10 de março de 2011, Maurits Casteels / British Airways plc, C-379/09, c. n. 14 e 15. Disponível em: <http://curia.europa.eu/juris/document/ document.jsf ? docid $=80426 \&$ mode $=$ req\&pageIndex $=3 \&$ dir $=\& o c c=$ first\&part $=1 \&$ text $=\% 2522$ efeito $\% 2$ Bdirecto\%2522\&doclang=PT\&cid=206561\#ctx1>. Acesso em: 11 jun. 2013; o Ac. TJUE 1 de julho de 2010, Susanne Gassmayr / Bundesminister für Wissenschaft und Forschung, C-194/08, c. n. 45. Disponível em: $<$ http://curia.europa.eu/juris/document/document.jsf ?docid $=79081 \&$ mode $=$ req\&pageIndex $=5 \&$ dir $=\& o c c$ $=$ first\&part=1\&text=\%2522efeito\%2Bdirecto \%2522\&doclang=PT\&cid=214756\#ctxl>. Acesso em: 11 jun. 2013, refere, por seu turno, que um preceito é incondicional "quando prevê uma obrigação que não é acompanhada de condições nem subordinada, na sua execução ou nos seus efeitos, à intervenção de qualquer acto das instituições da União ou dos Estados-membros", no que se afasta um pouco dum formulário antecedente, onde uma disposição era incondicional quando "não deixa[va] aos Estados-membros qualquer margem de apreciação" (Ac. TJCE 12 de dezembro de 1990, Kaefer e Procacci, C-100/89 e C-101/89, Col., pp. I-4647 ss., c. $\mathrm{n}^{\circ}$ 26, p. I-4674). Verifica-se outrossim alguma oscilação terminológica na doutrina, havendo quem refira a incondicionalidade duma norma à circunstância de esta se não encontrar sujeita a qualquer medida adicional da União ou dos Estados-membros, como FAIrHURST, John; Vincenzi, Christopher. Law of the European Community, 4. ed. Harlow: Longman, 2003. p. 188; para uma revisão doutrinária mais actual, p. ex.: LoRenzon, Sara. Op. cit.

13 No recente Ac. TJUE 1 de julho de 2010, Susanne Gassmayr / Bundesminister für Wissenschaft und Forschung, C-194/08, cit., c. n. 45, pode ler-se textualmente, citando jurisprudência anterior, que um preceito é suficientemente preciso "quando prevê uma obrigação em termos inequívocos".

14 Podem nomeadamente indicar-se, nas décadas de oitenta e noventa, o Ac. TJCE 20 de setembro de 1988, Oberkreisdirektor des Kreises Borken e outros / Moormann, 190/87, Col., p. 4689 ss., c. n. 23 e 24, p. 4722; o Ac. TJCE 22 de junho de 1989, Fratelli Costanzo / Comuna de Milão, 103/88, Col., p. 1839 ss., c. n. 29, p. 1870; o Ac. TJCE 27 de junho de 1989, Kühne / Finanzamt München III, 50/88, Col., p. 1925 ss., c. n. 23, p. 1955; o Ac. TJCE 12 de julho de 1990, Foster e outras, C-188/89, Col., p. I-3313 ss., c. n. 16 e 18, p. I-3347 e I-3348; o Ac. TJCE 30 de maio de 1991, Karella e Karellas, C-19/90 e C-20/90, Col., p. I-2691 ss., c. n. 17, p. I-2716; ou o Ac. TJCE 11 de julho de 1991, Verholen e outros, C-87/90, C-88/90 e C-89/90, Col., p. I-3757 ss., c. n. 14, p. I-3788. No presente, o Ac. TJUE 15 de novembro de 2011, Murat Dereci e o. / Bundesministerium für Inneres, C-256/11, cit., c. n. 87; o Ac. TJUE 21 de julho de 2011, Tural Oguz / Secretary of 
Pode aliás acrescentar-se, numa formulação mais detalhada dos apontados requisitos, ser necessário ocorrer o seguinte quadro: tratar-se de uma norma positiva (não meramente programática ${ }^{15}$ ); ser uma norma clara e precisa (não vaga ou demasiado genérica, nem equívoca); ser uma norma incondicional (não sujeita a reservas nem dependente de um facto ainda não realizado); ser uma norma completa e juridicamente perfeita (contendo todos os elementos necessários para ser efectivamente aplicada, não necessitando de quaisquer desenvolvimentos ou intervenções complementares de um Estado-membro ou de um órgão da União) ${ }^{16}$.

Servirá como ilustrativo do tema, à cabeça, o já citado Ac. Kaefer e Procacci, onde já se lê que constitui "jurisprudência assente que as disposições de uma decisão do Conselho produzem efeito directo nas relações entre os Estados-membros e os seus cidadãos, no sentido de que criam na esfera dos particulares direitos que os órgãos jurisdicionais nacionais devem proteger, quando tais disposições imponham aos Estados-membros uma obrigação incondicional e suficientemente clara e precisa" $"$. $\mathrm{O}$ acórdão acabado de transcrever louvou-se expressis verbis, entre outros,

State for the Home Department, C-186/10, c. $\mathrm{n}^{\circ}$ 23. Disponível em: <http://curia.europa.eu/juris/document/ document.jsf ?docid $=107930 \&$ mode $=$ req\&pageIndex $=1 \&$ dir $=\& o c c=$ first $\&$ part $=1 \&$ text $=\% 2522$ efeito $\% 2 B$ directo\%2522\&doclang=PT\&cid=206561\#ctx1>. Acesso em: 11 jun. 2013; o Ac. TJUE 22 de Dezembro de 2010, Rosa María Gavieiro Gavieiro e o. / Consellería de Educación e Ordenación Universitaria de la Xunta de Galicia, C-444/09 e C-456/09, c. n. 76 (falando de "jurisprudência assente"). Disponível em: $<$ http://curia.europa.eu/juris/document/document.jsf docid $=83450 \&$ mode $=$ req\&pageIndex $=2 \& \operatorname{dir}=\& o c c$ $=$ first\&part=1\&text=\%2522efeito\%2Bdirecto \%2522\&doclang=PT\&cid=206561\#ctx1>. Acesso em: 11 jun. 2013; ou ainda o Ac. TJUE 1 de julho de 2010, Susanne Gassmayr / Bundesminister für Wissenschaft und Forschung, C-194/08, cit., c. n 44 (aludindo também a "jurisprudência assente").

15 Uma norma positiva é aquela vocacionada, "devido ao seu peculiar conteúdo prescritivo e ao contexto onde se insere, para ser directamente aplicada ao caso concreto" (LoRENzon, Sara. Op. cit., p. 21-22).

16 Para esta súmula enunciativa, na doutrina, HANLON, James. European Community Law, 3. ed. London: Sweet \& Maxwell, 2003. p. 109; próximo na substância e notando corresponder a "jurisprudência constante", o enunciado de GROUSSOT, Xavier; PECH, Laurent. La protection des droits fondamentaux dans l'Union européenne après le Traité de Lisbonne", Questions d'Europe (Fondation Robert Schuman), n. 173, 14 juin 2010, p. 10. Disponível em: <http:/www.robert-schuman.eu/doc/questions_europe/qe-173-fr. pdf>. Acesso em: 9 mar. 2011.

17 Ac. TJCE 12 de dezembro de 1990, C-100/89 e C-101/89, cit., c. no 24, p. I-4673; mais recuadamente, Ac. TJCE 10 de julho de 1980, Marty/Lauder, 37/79, Rec., p. 2481 ss., c. nº 13, p. 2500. Na jurisprudência mais recente consagrou-se também, expressis verbis, que "segundo jurisprudência assente do Tribunal de Justiça, em todos os casos em que, do ponto de vista do seu conteúdo, as disposições de uma directiva se revelem incondicionais e suficientemente precisas, os particulares têm o direito de as invocar nos tribunais nacionais contra o Estado" (Ac. TJUE 24 de novembro de 2011, Asociación Nacional de Establecimientos Financieros de Crédito (ASNEF) e o. / Administración del Estado, C-468/10 e C-469/10, c. n 51. Disponível em: <http:/curia.europa.eu/juris/document/document.jsf ?docid=115205\&mode=req\&pageIndex $=1$ $\&$ dir $=\&$ occ $=$ first\&part $=1 \&$ text $=\% 2522$ efeito $\% 2$ Bdirecto $\% 2522 \&$ doclang $=$ PT\&cid=80820\#ctxl $>$. Acesso em: 10 jun. 2013). 
no Ac. Grad / Finanzamt Traunstein - e é deste último, abrindo excepção à regra de só fazermos uma transcrição para ilustrar cada ponto da exposição, que trazemos aliás à colação, por particularmente expressiva, a passagem onde reza que

\begin{abstract}
embora os efeitos duma decisão [dirigida aos Estados-membros] possam não ser idênticos aos duma disposição regulamentar, esta diferença não exclui que eventualmente o resultado final, consistente no direito, dos particulares, de dela se prevalecerem em justiça, seja o mesmo que o duma disposição regulamentar directamente aplicável; [...] convém portanto examinar caso a caso se a natureza, a economia e os termos da disposição em causa são susceptíveis de produzir efeitos directos nas relações entre o destinatário do acto e terceiros ${ }^{18}$.
\end{abstract}

IV. Mais complicadas se afiguram ser as coisas, no concernente à expressão aplicabilidade directa.

a) Em alguma jurisprudência, deparamos com uma formulação que, pondo a tónica na atribuição de direitos subjectivos, parece, ao menos formalmente, aproximar-se do acima retratado pela expressão efeito directo. Sirva de ilustração o Ac. Administração das Finanças do Estado / Simmenthal, para o qual "a aplicabilidade directa [...] significa que as regras do direito comunitário devem desenvolver a plenitude dos seus efeitos, duma maneira uniforme em todos os Estados-membros, a partir da sua entrada em vigor e durante todo o seu período de validade" (c. n ${ }^{\circ}$ $14) ; “[\ldots]$ assim, tais disposições são uma fonte imediata de direitos e de obrigações para todos aqueles a quem dizem respeito, sejam Estadosmembros ou particulares sujeitos de relações jurídicas relevando do direito comunitário" (c. $\left.\mathrm{n}^{0} 15\right)^{19}$.

b) A proximidade entre a designação aplicabilidade directa, ou designações do tipo aplicabilidade directa, e conteúdos do género do supra exposto (em III.) como correspondente a efeito directo (uma usada como rótulo do outro?...), é por vezes ainda mais nítida. Atentemos a propósito no trecho, extractado do Ac. proferido no Proc. C-120/88, Comissão / Itália, onde, com referência ao Tratado CEE, o Tribunal de Justiça fala da "faculdade concedida aos administrados de invocar perante os órgãos jurisdicionais nacionais as disposições directamente aplicáveis do Tratado"20.

\footnotetext{
18 Ac. TJCE 6 de outubro de 1970, 9/70, Rec., p. 825 ss., c. $n^{\circ} 5$, p. 839.

19 Ac. TJCE 9 de março de 1978, 106/77, Rec., p. 629 ss., p. 643.

20 Ac. TJCE 26 de fevereiro de 1991, Col., p. I-621 ss., c. n 10, p. I-638. Algumas linhas acima,
} aliás, no c. $\mathrm{n}^{\circ} 5$ deste acórdão, e também com relação ao artigo $95^{\circ}$ do Tratado CEE, o Tribunal ponderara 
c) Noutros pronunciamentos (e sem deixar embora, note-se, de aludir também a "efeitos imediatos" ${ }^{\text {e }}$ "efeitos directos"), o Tribunal de Justiça põe a tónica numa realidade distinta: a aplicabilidade directa seria essencialmente a característica, de dadas disposições do Direito Comunitário, de entrarem só por si a fazer parte da Ordem Jurídica dos Estados-membros, independentemente de mediação destes - e sem que estes possam aliás fazer algo para impedir tal entrada. Olhemos o Ac. Bussone / Ministério Italiano da Agricultura, onde reza que "nos termos do artigo $189^{\circ}$, segundo parágrafo, do Tratado [CEE], o regulamento tem carácter geral e é directamente aplicável em todos os Estados-

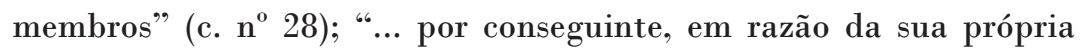
natureza e da sua função no sistema das fontes de direito comunitário, ele produz efeitos imediatos" (c. $\left.\mathbf{n}^{\circ} 29\right)$; "a aplicabilidade directa dum regulamento exige que a sua entrada em vigor e a sua aplicação beneficiando ou onerando sujeitos de direito ocorram sem qualquer medida de recepção por parte do direito nacional" (c. $\left.\mathbf{n}^{\circ} 30\right)^{22}$.

que este "produz efeitos directos e cria para os particulares direitos que os órgãos jurisdicionais nacionais devem proteger" (p. I-637). Cf., para estabelecer ponte de ligação, o que dizemos já de seguida (infra, V.).

${ }^{21}$ Em jurisprudência relativamente recente, o Tribunal de Justiça veio consignar expressamente, num pronunciamento onde se refere à aplicabilidade directa, que "as disposições dos regulamentos produzem, em geral, efeitos imediatos nas ordens jurídicas nacionais, sem que seja necessário as autoridades nacionais tomarem medidas de aplicação", o que parece esclarecer satisfatoriamente o alcance que atribui à expressão "efeito imediato", aliás aparentemente identificada, um pouco abaixo, com a expressão "aplicabilidade imediata" (Ac. TJCE 24 de junho de 2004, Herbert Handlbauer GmbH, C-278/02, respectivamente c. $\mathrm{n}^{\circ} 25$ e c. $\mathrm{n}^{\circ}$ 28. Disponível em: <http://curia.europa.eu/juris/document/document.jsf?docid=49312 $\&$ mode $=$ req $\&$ pageIndex $=6 \&$ dir $=\&$ occ $=$ first $\&$ part $=1 \&$ text $=\% 2522$ directamente $\% 2 \mathrm{Baplic} \% 25 \mathrm{C} 3 \% 25$ Alvel\%2522\&doclang=PT\&cid=420429\#ctxl>. Acesso em: 13 jun. 2013).

22 Ac. TJCE 30 de novembro de 1978, 31/78, Rec., p. 2429 ss., p. 2444. Com formulações próximas e conducentes ao mesmo alcance: Ac. TJCE 17 de maio de 1972, Leonesio / Ministério italiano da Agricultura, 93/71, Rec., p. 287 ss., c. n 5 e 6, p. 294; Ac. TJCE 31 de janeiro de 1978, Zerbone / Amministrazione delle finanze dello Stato, 94/77, Rec., p. 99 ss., c. n 24, p. 116; e Ac. TJCE 28 de março de 1985, Comissão / Itália, 272/83, Rec., p. 1057 ss., c. $\mathrm{n}^{\circ}$ 26, p. 1074. Na actualidade, reiterando que a aplicabilidade directa dum regulamento impõe que a sua entrada em vigor e a sua aplicação ocorram sem qualquer medida de recepção do Direito Nacional, valha o Ac. TJUE 14 de julho de 2011, Bureau national interprofessionnel du Cognac, C-4/10 e C-27/10, c. $\mathrm{n}^{\circ}$ 66. Disponível em: <http://curia.europa.eu/juris/document/document. jsf ? docid $=107353 \&$ mode $=$ req\&pageIndex $=1 \&$ dir $=$ \&occ $=$ first \&part $=1 \&$ text $=\% 2522$ aplicabilidade $\% 2$ Bdirecta \%2522\&doclang=PT\&cid=291980\#ctxl>. Acesso em: 12 jun. 2013; ou o Ac. TJUE 5 de outubro de 2010, Comissão / França, C-512/08, c. nº 53. Disponível em: <http://curia.europa.eu/juris/document/document.jsf ?docid $=81397 \&$ mode $=$ req\&pageIndex $=2 \&$ dir $=\& o c c=$ first $\&$ part $=1 \&$ text $=\% 2522$ directamente \%2Baplic\%25C3\%25Alvel\%2522\&doclang=PT\&cid=314174\#ctxl>. Acesso em: 12 jun. 2013. Conduzindo, em nosso entender, ao mesmo resultado, pode ler-se, noutra sentença ainda recente, que "a escolha da forma de regulamento, em vez da forma de directiva [...], prova a importância que o legislador comunitário 
V. Se, relativamente ao conjunto dos arestos já arrolados, não pode pôr-se de parte (ou pode até legitimamente equacionar-se, mais ou menos tendencialmente) uma ideia genérica de conglomeração, muitos outros acórdãos parecem corroborar essa impressão de um englobamento das realidades aplicabilidade directa e efeito directo, nem que seja ao menos com indistinção terminológica e na modalidade de englobamento parcial. O que se segue não se opõe, por conseguinte, ao que se já disse, vindo antes na sua lógica sequência ${ }^{23}$.

a) Antes de mais, temos as situações nas quais o juiz comunitário diz, de certa disposição do Tratado, que esta tem efeito directo e atribui direitos. Pode exemplificar-se com o Ac. Delimitis, no qual o juiz comunitário afirma que “os artigos $85^{\circ}, \mathrm{n}^{\circ} 1$, e $86^{\circ}$ [do Tratado CEE] produzem efeitos directos nas relações entre os particulares e atribuem directamente aos sujeitos jurídicos direitos que os órgãos jurisdicionais nacionais devem salvaguardar" ${ }^{\text {}}$. Seja qual for o alcance daquela conjunção copulativa "e", afigura-se de bom método, dada a ausência de elementos que apontem decisivamente em sentido diverso, partir da ideia de que ela traduza o seu normal significado gramatical: o de soma (ou englobamento).

b) O que vem de dizer-se na alínea anterior vale de pleno para o caso de o Tribunal Comunitário se referir a uma disposição do Tratado, dizendo que a mesma tem aplicabilidade directa e atribui direitos. Desta formulação é ilustrativo o Ac. Pigs Marketing Board / Redmond, para o qual “[a]s disposições dos artigos $30^{\circ}$ e $34^{\circ}$ do Tratado CEE [...] são directamente aplicáveis e atribuem aos particulares direitos que os órgãos jurisdicionais dos Estados-membros são obrigados a salvaguardar" ${ }^{925}$.

atribuiu à aplicabilidade directa das disposições do referido regulamento e à sua aplicação uniforme" (Ac. TJCE 8 de novembro de 2005, Götz Leffler / Berlin Chemie AG, C-443/03, c. nº 46. Disponível em: <http:// curia.europa.eu/juris/document/document.jsf ?docid $=55594 \& \operatorname{mode}=\mathrm{req} \&$ pageIndex $=1 \& \operatorname{dir}=\&$ occ $=$ first \&part=1\&text=\%2522aplicabilidade \%2Bdirecta \%2522\&doclang=PT\&cid=230961\#ctx1>. Acesso em: 12 jun. 2013).

${ }^{23}$ De entre a doutrina que salientou a mencionada ambiguidade ou indistinção, por todos, HANLON, James. Op. cit., p. 107.

24 Ac. TJCE 28 de fevereiro de 1991, C-234/89, Col., p. I-935 ss., c. nº 45, p. I-992. Elencamos complementarmente o Ac. TJCE 30 de abril de 1974, Sacchi, 155/73, Rec., p. 409 ss., al. 5) do disposit., p. 432; e o Ac. TJCE 14 de julho de 1976, Donà / Mantero, 13/76, Rec., p. 1333 ss., al. 2) do disposit., p. 1342.

25 Ac. TJCE 29 de novembro de 1978, 83/78, Rec., p. 2347 ss., al. 2) do disposit., p. 2377. Na jurisprudência actual, cremos ir em igual sentido a tirada do Tribunal de Justiça quando, acerca duma 
c) Por outro lado, e caso se comparem entre si alguns acórdãos, constatase que o juiz comunitário, sem debruar conceitos, fala de aplicabilidade directa e de efeito directo acerca daquilo que podemos deduzir ser o mesmo universo temático. É assim que, por exemplo, o Tribunal de Justiça veio afirmar, no Ac. Administração das Finanças do Estado / Essevi e Salengo, que o "artigo $95^{\circ}$ [do Tratado CEE], e a questão da sua aplicabilidade directa são objecto duma jurisprudência antiga, abundante e diversificada, que não deixa subsistir dúvidas sobre o alcance desta disposição" ${ }^{" 26}$. Isto, depois de anos antes ter dito, no Ac. Fink-Frucht, que o par. 2 desse artigo era "susceptível de produzir efeitos imediatos"27. E também depois de ter sentenciado, no Ac. Molkerei-Zentrale, que o par. 1 do mesmo artigo era "susceptível de produzir efeitos directos ${ }^{928} 29$.

directiva, sentenciou que "a circunstância de determinadas disposições da directiva em causa serem directamente aplicáveis no ordenamento jurídico interno não é uma justificação que dispense os Estadosmembros do seu dever de transposição" (Ac. TJCE 3 de dezembro de 2009, Comissão / Bélgica, C-475/08, c. $\mathrm{n}^{\circ}$ 44. Disponível em: <http://curia.europa.eu/juris/document/document.jsf ?docid=73874\&mode=req \&pageIndex $=1 \& \operatorname{dir}=\&$ occ $=$ first\&part $=1 \&$ text $=\% 2522$ aplicabilidade $\% 2$ Bdirecta $\% 2522 \&$ doclang $=\mathrm{PT}$ \&cid=295740\#ctx1>. Acesso em: 12 jun. 2013); tendo em atenção um regulamento, pode ver-se também o ainda recente Ac. TJCE 14 de fevereiro de 2008, Sophiane Gysen / Groupe S-Caisse d'Assurances sociales pour indépendants, C-449/06, c. $\mathrm{n}^{\circ}$ 25. Disponível em: <http://curia.europa.eu/juris/document/document.jsf? docid $=71572 \&$ mode $=$ req\&pageIndex $=4 \&$ dir $=\&$ occ $=$ first $\&$ part $=1 \&$ text $=\% 2522$ directamente $\% 2 \mathrm{Baplic} \%$ 25C3\%25Alvel\%2522\&doclang=PT\&cid=258523\#ctx1>. Acesso em: 12 jun. 2013, bem como o Ac. TJCE 13 de outubro de 2005, Richard Dahms GmbH / Fränkischer Weinbauverband eV, C-379/04, c. n ${ }^{\circ}$ 13. Disponível em: <http://curia.europa.eu/juris/document/document.jsf ?docid=60257\&mode=req\&pageIndex $=5 \&$ dir $=$ \&occ $=$ first \&part $=1 \&$ text $=\% 2522$ directamente $\% 2$ Baplic $\% 25 \mathrm{C} 3 \% 25 \mathrm{Alvel} \% 2522 \&$ doclang $=\mathrm{PT} \& c i d$ =408822\#ctxl>. Acesso em: 13 jun. 2013; considerando uma disposição do Tratado Institutivo, o Ac. TJCE 18 de dezembro de 2007, Laval un Partneri Ltd / Svenska Byggnadsarbetareförbundet e o., C-341/05, c. $\mathrm{n}^{\circ} 97$. Disponível em: <http://curia.europa.eu/juris/document/document.jsf?text=\%2522directamente\%2Baplic $\% 25 \mathrm{C} 3 \% 25 \mathrm{Al}$ vel $\% 2522 \&$ docid=71925\&pageIndex $=0 \&$ doclang $=$ pt\&mode $=$ req\&dir $=\&$ occ $=$ first\&part $=1 \& c i d=408822 \#$ ctxl>. Acesso em: 13 jun. 2013.

26 Ac. TJCE 27 de maio de 1981, 142 e 143/80, Rec.,p. 1413 ss., c. nº 33, p. 1437.

${ }^{27}$ Ac. TJCE 4 de abril de 1968, 27/67, Rec., p. 327 ss., $\mathrm{n}^{\circ} 2^{\circ}$ do disposit., p. 344.

28 Ac. TJCE 3 de abril de 1968, 28/67, Rec., p. 211 ss., p. 226.

${ }^{29}$ Em jurisprudência mais recente, julgamos significativa a passagem onde se consigna que "sempre que as disposições de uma directiva sejam, do ponto de vista do seu conteúdo, incondicionais e suficientemente precisas, essas disposições podem, na ausência de medidas de transposição adoptadas no prazo fixado, ser invocadas contra qualquer disposição nacional não conforme à directiva, ou ainda se forem de natureza a definir direitos que os particulares possam alegar contra o Estado" (Ac. TJCE 9 de setembro de 2004, Meiland Azewijn BV / Hauptzollamt Duisburg, C-292/02, c. nº 57, Disponível em: <http://curia. europa.eu/juris/document/document.jsf $?$ docid $=49469 \&$ mode $=$ req \&pageIndex $=6 \&$ dir $=\& o c c=$ first \&part $=1 \&$ text $=\% 2522$ directamente $\% 2$ Baplic $\% 25 \mathrm{C} 3 \% 25$ Alvel $\% 2522 \&$ doclang $=$ PT\&cid=420429\#ctx $1>$. Acesso em: 13 jun. 2013). 
VI. Fazendo um apanhado de ideias, repetimos que, em nosso entender, os dados da jurisprudência, pela heterogeneidade que em bom rigor apresentam, não permitem tirar conclusão categórica num ou noutro sentido. Importa de resto acrescentar que também se encontram acórdãos nos quais o juiz comunitário não usa qualquer denominação, limitando-se a dizer, como v.g. no Ac. Watson e Belmann, que determinadas disposições (no caso, do Tratado CEE) "atribuem às pessoas a que respeitam direitos individuais que os órgãos jurisdicionais nacionais devem salvaguardar" ${ }^{" 30}$.

Sem embargo, não nos repugna crer que o Tribunal dê prevalência à ideia do englobamento, ideia que se nos afigura aparecer sobremodo glosada; aliás, se o que afinal o Tribunal defende for a ideia do englobamento parcial, subscreverá aquele que consideramos ser o melhor entendimento ${ }^{31}$ : na verdade, caso se considere que há uma zona de sobreposição entre aplicabilidade directa e efeito directo, zona essa para cujo traçado desempenha fundamental papel um vector meramente temporal, bem se explica (e se admite) que, em linguagem corrida, se identifiquem ambas as realidades pela mesma expressão, uma vez que ambas apresentam identidade de natureza. Insiste-se no entanto, em suma, a jurisprudência está longe de ser líquida.

VII. Resta um apontamento metodológico: num estudo de dimensão exígua, o desejo de expor alguma investigação e reflexão obriga normalmente a opções delicadas; este não fugiu à regra, pelo que tivemos de jogar com uma escolha de base; e essa escolha foi, sem esquecer o relevo dos contributos doutrinários, a de termos dado tendencial preferência, quanto ao material de observação, à exposição da jurisprudência.

Fizemo-lo por duas razões essenciais. Primeira e principal razão: é que foi sobre a jurisprudência que a doutrina comunitária se centrou nesta temática; o que não é aliás de estranhar, já que a construção da atribuição directa de direitos aos particulares, para além da letra do Tratado, é obra do Tribunal de Justiça ${ }^{32}$ (inserido

30 Ac. TJCE 7 de julho de 1976, Watson e Belmann, 118/75, Rec., p. 1185 ss., al. 1) do disposit., p. 1200. Como meros outros exemplos, pode ver-se o Ac. TJCE 14 de julho de 1971, Ministério Público luxemburguês / Muller, 10/71, Rec., p. 723 ss., designadamente c. $\mathrm{n}^{\circ}$ 16, p. 730; e, bastantes anos volvidos, o Ac. TJCE 7 de fevereiro de 1991, Nimz, C-184/89, Col., p. I-297 ss., c. nº 17, p. I-320.

${ }^{31}$ Cf. infra, em particular $\mathrm{n}^{\circ} 3$, ponto I.

${ }^{32}$ Numa afirmação global actual, por todos, LoRenzon, Sara. Op. cit., p. 5. 
de resto num percurso genérico amiúde "marcadamente pretoriano e pioneiro" dando assim nota dum "activismo judicial" ${ }^{34}$ pouco comum nos países de tradição jurídica romano-germânica ${ }^{35}$ (e por isso algo difícil de aceitar por estes ${ }^{36}$ ), mas oriundo duma dialéctica ${ }^{37}$ resultante dos importantes poderes conferidos àquele Tribunal $^{38}$ (embora deva anotar-se que, como mais recentemente salientou DE MOL, uma postura muito ousada do Tribunal pode levantar problemas essenciais em sede da temática do princípio do equilíbrio institucional ${ }^{39}$ ).

A segunda razão da nossa opção consiste na circunstância de alguma doutrina ter reduzido esta problemática, a uma questão meramente terminológica (redução expressa ou implícita ${ }^{40}$ ), posição esta que já afirmámos não ser a nossa e

33 GASPAR, António Henriques. O Direito europeu em acção: a jurisprudência do Tribunal de Justiça da União Europeia. In: FERREIRA, E. P. (Org.): Justiça Nacional, Justiça Europeia: a jurisprudência do Tribunal de Justiça da União Europeia, Coimbra: Almedina, 2011. p. 37-52, p. 42.

34 FERREIRA, Eduardo Paz. Sessão de abertura da Pós-Graduação em Jurisprudência da União Europeia 2010-1011. In FERREIRA, E. P. (Org.): Justiça Nacional, Justiça Europeia: a jurisprudência do Tribunal de Justiça da União Europeia. Coimbra: Almedina, 2011. p. 5-15, p. 11. De notar que a doutrina sublinha que o Tribunal "desenvolveu vários princípios" do Direito da União (CICCI S., Gilda. La responsabilidad del Estado por violación del derecho comunitario: jurisprudencia del Tribunal de Justicia. Ars Boni et Aequi: Revista Jurídica de la Universidad Bernardo O'Higgins, enero 2010, año 6, n. 1, p. 9-25, p. 11).

35 Protagonizando afinal um labor "continental quanto à definição e aplicação de princípios e anglo-saxónico quanto ao método" (RODRIGUES, José Narciso Cunha. Alguns temas e múltiplos desafios. In: FERREIRA, E. P. (Org.): Justiça Nacional, Justiça Europeia: a jurisprudência do Tribunal de Justiça da União Europeia. Coimbra: Almedina, 2011. p. 17-35, p. 24).

${ }^{36}$ É assim que, tendo em atenção a vexata quaestio da jurisprudência como fonte do Direito, não falta quem opine que "seria mais adequado que o efeito direto, jurisprudencialmente reconhecido, se plasmasse no articulado dos Tratados", como LÓPEZ DE LOS MOZOS DÍAZ-MADROÑERO, Alicia. La normativización de la jurisprudencia del Tribunal de Justicia de las Comunidades Europeas. Revista General de Derecho Público Comparado, 2008, n. 3, p. 1-17, p. 17. Disponível em: <http://www.iustel.com>. Acesso em: 23 maio 2013.

${ }^{37}$ Por vezes assente numa finalidade político-jurídica, como ressalta BONGIOVANNI, Veronica. Riflessi privatistici in materia contrattuale del principio comunitario di non discriminazione. Comparazione e diritto civile, dicembre 2010, p. 7. Disponível em: <http:/www.comparazionedirittocivile.it/prova/files/ buongiovanni_riflessi.pdf $>$. Acesso em: 27 maio 2013.

38 Por todos, MENGOZZI, Paolo. Op. cit., p. 145.

39 DE MOL, Mirjam. The novel approach of the CJEU on the horizontal direct effect of the EU principle of non-discrimination: (unbridled) expansionism of EU Law? Maastricht Journal of European and Comparative Law, 2011, v. 18, n. 1, p. 109-135, p. 110. Veja-se também, numa óptica aparentemente mais "moderada" sobre as profundas eventuais implicações do papel assumido pelo Tribunal de Justiça, LOPES, Dulce. Principais contributos da União Europeia e do Conselho da Europa em matéria de não discriminação. Debater a Europa, jan.-jun. 2011, n. 4, p. 32-61, nomeadamente p. 45. Disponível em: <http://euro pe-direct-aveiro.aeva.eu/debatereuropa/images/n4/principais.pdf>. Acesso em: 23 maio 2013.

${ }^{40}$ Cremos lobrigar uma redução implícita ao campo da mera terminologia, entre outros, em 
demonstraremos por quê; mas posição que, a ser correcta, retiraria boa parte do interesse de ajuntar alguns elementos para consideração.

I. Chegados aqui, importa, em primeiro lugar, fixarmos o conteúdo que, em nossa opinião, deve corresponder às expressões aplicabilidade directa e efeito directo.

Para nós é de entender, por aplicabilidade directa, a característica, de dadas disposições do Direito Comunitário, de entrarem só por si a fazer parte da Ordem Jurídica dos Estados-membros (ou seja, independentemente de mediação destes) ${ }^{41}$, atribuindo e impondo respectivamente direitos e deveres aos sujeitos jurídicos destinatários, sempre que for o caso. Por que esta frase final e o seu sublinhado? Duma banda, sublinhámos propositadamente direitos, para focar a atenção no elemento-base de ligação à sequência da nossa exposição; doutra banda, o deixarse na sombra o aspecto traduzido por esta frase final, falando da aplicabilidade directa apenas como uma técnica ou forma de incorporação do Direito Comunitário na Ordem Jurídica dos Estados-membros, levaria a um retrato não fiel da realidade (por reduzir esta, ou ao menos a sua descrição, ao resultado da observação feita por uma óptica de visão incompleta).

Por sua vez, a expressão efeito directo significa a característica, de certas disposições do Direito Comunitário (desde que incondicionais e suficientemente precisas), de serem base válida para atribuir aos particulares direitos ${ }^{42}$ que estes podem invocar perante os órgãos jurisdicionais nacionais. ${ }^{43}$

UGARTEMENDÍA, Juan Ignacio; SARMiENTO, Daniel. La protección de los derechos fundamentales del ciudadano europeo en tránsito: ¿Cuestión interna o comunitaria?, InDret: Revista para el Análisis del Derecho, enero 2008, n. 1, passim. Disponível em: <http://www.indret.com/pdf/498_es.pdf>. Acesso em: 24 maio 2013.

${ }^{41}$ Assim, p. ex., FAIRHURST, John; VINCENZI, Christopher. Op. cit., p. 190; ou ZANGHÌ, Claudio. Istituzioni di diritto dell'Unione Europea: verso una Costituzione Europea. 4. ed., Torino: Giappichelli, 2003. p. 279.

42 Como ilustração doutrinária recente de que o efeito directo "não pode implicar o prejuízo dum sujeito, mas apenas um benefício" (BIN, Roberto. Nota brevissima su uno strano caso di disapplicazione della legge tributaria a danno del privato, per contrasto con una direttiva europea. 12 luglio 2012. Disponível em: <http://www.forumcostituzionale.it/site/images/stories/pdf/documenti_forum/giurisprudenza/giurisdi zioni_ordinarie/0012_bin.pdf>.Acesso em: 27 maio 2013).

43 Na mesma linha de caracterização da aplicabilidade directa e do efeito directo, por todos, ZAMORANO-GUZMÁN, Cristian. La gobernanza de la Unión Europea:pPrincipio de primacía, efecto directo y traumatismo fundador. Revista de Derecho (Pontificia Universidad Católica de Valparaíso), 2008, n. XXXI, pp. 471-490, p. 481. Disponível em: <http:/www.scielo.cl/pdf/rdpucv/n31/al3.pdf>. Acesso em: 23 maio 2013; LORENZON, Sara. Op. cit., p. I; RACCAH, Aurélien. L'accès aux normes de l'Union, composante de 
II. Falando em termos gerais de dogmática jurídica, a diferenciação de conceitos $^{44}$ justifica-se, antes de mais, quando assim se represente uma tradução de conteúdos jurídicos totalmente diferentes. Para além destes casos, a criação de subconceitos (como espécie dentro do género diferenciação de conceitos) é útil (e portanto tecnicamente desejável), se constituir (como deve) uma rotulagem unívoca de aspectos específicos duma realidade mais ampla.

III. E é por esta última razão que entendemos útil a explicitação formal, como subconceito, da figura do efeito directo, parte integrante duma realidade mais ampla (a do conceito denominado aplicabilidade directa).

$\mathrm{O}$ que fica dito exige - ou ao menos aconselha, no tocante à alínea $a$ ) sequente - a demonstração de que:

a) $\mathrm{O}$ fundamento do efeito directo não se distingue do fundamento da aplicabilidade directa (identidade de fundamentos).

b) Constituindo o efeito directo uma "zona" totalmente dentro do "círculo" mais amplo aplicabilidade directa, há, em todas as situações nas quais ocorra efeito directo, forçosamente aplicabilidade directa (efeito directo implica aplicabilidade directa, contendo-se nesta).

c) Mas poderão, ao invés, ocorrer situações de aplicabilidade directa nas quais se não verifique o efeito directo (ou seja, aplicabilidade directa pode não implicar efeito directo, contraprova esta de que a aplicabilidade directa é realidade mais ampla que o efeito directo).

leur application directe. Jurisdoctoria, octobre 2008, n. 1, p. 91-116, p. 93. Disponível em: < http://www.juris doctoria.net/pdf/numerol/NUMERO_1.pdf>. Acesso em: 24 maio 2013; ou KESSEBOHM, Ricarda. Das Gemeinschaftsrecht im englischen Rech. Seminararbeit im Gebiet Die Stellung von Europa- und Völkerrecht im nationalen Recht, unter der Leitung von Prof. Dr. Mahulena Hofmann, Justus-Liebig-Universität Gießen, 2007, p. 1. Disponível em: <http://www.recht.uni-giessen.de/wps/fb01/dl/down/open/hofmann/6d14a 0c6914398874529d82a9b17092cf5bd649cfc8d76802c192522d4658b82a6341f956822d75bea3cb411ec01c524/ EG_Recht_in_Gro_britannien.pdf>.Acesso em: 26 maio 2013. Em doutrina menos recente, VILAÇA, José Luís da Cruz. A propósito dos efeitos das directivas na ordem jurídica dos Estados-membros. Cadernos de Justiça Administrativa, nov.-dez. 2001, n. 30, p. 3-19, passim. Diferentemente, propondo uma ampliação do conceito de efeito directo ("eficacia directa"), p. ex.: MARTÍNEZ CAPDEVILA, Carmen. Otra virtualidad de las directivas: su "efecto directo de exclusión”. Revista Electrónica de Estudios Internacionales, diciembre 2006, n. 12, p. 21. Disponível em: <http://www.reei.org/index.php/revista/num12/archivos/MtnezCap devila(reei12).pdf $>$. Acesso em: 23 maio 2013, para quem aquele expediente deveria comportar também, nomeadamente, "a invocabilidade duma directiva como parâmetro de aplicabilidade do Direito Nacional".

${ }^{44}$ Um panorama muito sintético da distinção entre os conceitos de efeito directo e de aplicabilidade directa pode ver-se, na doutrina recente, em MIRAGLIA, Michele. La responsabilità dello Stato per violazione del diritto dell'Unione europea da parte dell'organo giurisdizionale: la cronaca di una morte annunciata. Amministrazione in Cammino, febbraio 2012, p. 4, nota 11. Disponível em: <http://www.ammi nistrazioneincammino.luiss.it/?p=17485>. Acesso em: 27 maio 2013. 
Percorramos pois os pontos a demonstrar, começando pela alínea a); vale dizer, pelos fundamentos de ambas as figuras.

\section{IDENTIDADE DE FUNDAMENTOS DA APLICABILIDADE DIRECTA E DO EFEITO DIRECTO}

Aplicabilidade directa e efeito directo têm rigorosamente os mesmos fundamentos. São eles, numa possível e sucinta enumeração: o primado do Direito Comunitário; a necessidade de comunitarizar ou harmonizar progressivamente as Ordens Jurídicas Nacionais com a Ordem Jurídica Comunitária; e a necessidade de obter a uniformidade de aplicação do Direito Comunitário no espaço territorial das Comunidades ${ }^{45}$.

Sem com isto querermos dizer que seja relativamente menos importante ${ }^{46}$, não nos deteremos neste ponto ${ }^{47}$. En passant, notaremos apenas:

Quanto ao primado, que ele somente pode ficar garantido quando os Estados-membros não possam obstaculizar à regência da vida jurídica pelas normas do Direito Comunitário, seja por modo activo (criando ou mantendo em vigor normas contrárias a este) seja por modo passivo (não criando normas por ele reclamadas). ${ }^{48}$

${ }^{45}$ Em termos de alusão a artigos de lei (ou, se quisermos, de fundamento próximo), e com referência ao efeito directo das directivas, o Tribunal de Justiça teve em tempo ocasião de dizer que "o direito de um particular invocar contra um Estado-membro que se absteve de transpor para a sua ordem jurídica uma directiva, ou não o fez de modo adequado, uma disposição incondicional e suficientemente precisa da mesma, encontra o seu fundamento nas disposições conjugadas dos artigos $189^{\circ}$, terceiro parágrafo, e $5^{\circ}$ do Tratado CEE" (Ac. TJCE 20 de setembro de 1988, Oberkreisdirektor des Kreises Borken e outros / Moormann, 190/87, cit., c. $\mathrm{n}^{\circ} 24$, p. 4722$)$.

${ }^{46} \mathrm{O}$ efeito directo representa um proeminente expediente de resolução de dificuldades e conflitos de relação entre o Direito da União e os Direitos Nacionais (JANS, Jan H. European Environmental Law before Dutch Courts: observations on direct effect and consistent interpretation, december 9, 2011, p. 2 (pagin. electrón.). Disponíel em: <http://ssrn.com/abstract=1970270>. Acesso em: 24 maio 2013).

${ }^{47}$ Há quem aponte ao efeito directo uma essencial função sancionatória, como SARMIENTO, Daniel. Un paso más en la constitucionalización del tercer pilar de la Unión Europea: la sentencia Maria Pupino y el efecto directo de las decisiones marco. Revista electrónica de estudios internacionales, diciembre 2005, n. 10, passim. Disponível em: <http:/www.reei.org/index.php/revista/num10/archivos/D.Sarmien to(reeil0).pdf>. Acesso em: 24 maio 2013; em doutrina algo mais recuada, SOARES, António Goucha. Direito Comunitário: relatório sobre o programa, os conteúdos e os métodos do ensino da disciplina, Socius

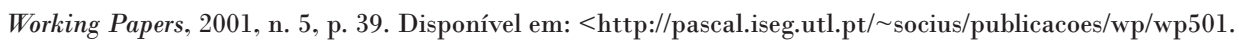
pdf>. Acesso em: 26 maio 2013. Tal entendimento, como resulta do texto, não desperta a nossa concordância, pelo menos (que mais não fosse) quanto ao seu carácter de "essencialidade".

${ }^{48}$ Na doutrina, por todos, MENGOZZI, Paolo. Op. cit., p. 151. Sobre os particulares problemas suscitados, relativamente ao primado, na área do Direito Criminal, SCHIATTI, Daniela. Quale primato del 
Quanto à integração ou harmonização jurídica, que ela é o próprio cerne do processo integrativo comunitário, já que a União Europeia é, summo rigore, um edifício jurídico. ${ }^{49}$

Quanto, finalmente, à uniformidade de aplicação do Direito Comunitário, que esta é a única maneira de se conseguir um espaço jurídico verdadeiramente integrado; de pouco serviria a existência de um processo legislativo integrado, se a execução das respectivas leis apresentasse divergências insanáveis ou de difícil sanação $^{50}$, para além de que as disparidades de estatuto jurídico se traduziriam assim em discriminações de cidadãos de certos Estados-membros relativamente a outros $^{51}$.

IDENTIDADE DE NATUREZA DA APLICABILIDADE DIRECTA E DO EFEITO DIRECTO, COM DIFERENÇAS DE AMPLITUDE

\subsection{O EFEITO DIRECTO IMPLICA, E CONTÉM-SE, NA APLICABILIDADE DIRECTA}

I. Dissemos acima que, em todas as situações em que se verifique efeito directo, verificar-se-á necessariamente aplicabilidade directa. Tal afirmação poderá parecer paradoxal, tanto mais quanto é certo que a invocação do efeito directo, pelos particulares, pode justamente ter por base normas constantes por exemplo de uma directiva comunitária, acto que, prima facie, parece desprovido de aplicabilidade directa.

II. Em nosso entender, a chave do aparente paradoxo pode encontrar-se na referência da característica da aplicabilidade directa, não ao acto jurídico-

\footnotetext{
diritto comunitario in ambito penale?. Rivista di Diritto Internazionale Privato e Processuale, aprile-giugno 2008, anno XLIV, n. 2, pp. 479-504.

${ }^{49}$ A ideia da especificidade da Comunidade (e da União) Europeia tem sido por vezes invocada na doutrina como timbre por excelência do respectivo Direito: "No seu ponto de partida os Tratados que instituem a Comunidade Europeia são simples tratados internacionais. Mas por causa da autonomia da Ordem Jurídica Comunitária, têm em si mesmos aplicabilidade directa nos Estados-membros." (FRANCK, Gunnar: "Die horizontale unmittelbare Anwendbarkeit der EG-Grundfreiheiten: Grundlagen und aktuelle Entwicklung. Beiträge zum Europa - und Völkerrecht, januar 2009, heft 1, p. 7. Disponível em: <http://telc. jura.uni-halle.de/sites/default/files/telc/Heftl.pdf>. Acesso em: 26 maio 2013).

${ }^{50}$ Na doutrina, por todos, MENGOZZI, Paolo. Op. cit., p. 151.

${ }^{51}$ Na doutrina, por todos, RACCAH, Aurélien. Les effets de l'application directe du Droit de l'Union par les autorités régionales et locales européennes sur l'Ordonnancement Juridique des États Membres: les exemples allemand, britannique et français. European Journal of Legal Studies, 2008, v. 2, n. 1, p. 269-285, nomeadamente p. 272. Disponível em: <http://www.ejls.eu/4/59FR.pdf>. Acesso em: 24 maio 2013.
} 
normativo (fonte de direito) considerado globalmente, mas sim ao seu conteúdo normativo - ou seja, ao conjunto das normas que o compõem; sem perder de vista, numa palavra, a individuação das normas dele constantes. Notemos aliás, como pode ver-se por jurisprudência oportunamente citada, como o Tribunal Comunitário, ao abordar a temática aplicabilidade directa / efeito directo, se refere a disposições ou artigos (do Tratado Institutivo, de directivas...).

III. A adopção do ponto de vista exposto não corresponde a um bizantinismo de raciocínio. Ela permite, de facto, compreender o aparente paradoxo.

Imagine-se uma directiva comunitária. Expirado o tempo dado ao Estadomembro para proceder à respectiva transposição, ou seja, para dar execução às determinações nela insertas, o particular que se veja afectado pela inacção desse Estado pode, dentro de certas condições, invocar direitos decorrentes dessa directiva.

Dir-se-á: eis um caso em que há que invocar o efeito directo, precisamente por não se poder invocar a aplicabilidade directa. Mas uma pergunta é cabida: não existindo aplicabilidade directa, como pode surgir, na esfera jurídica do particular, o direito subjectivo que surgiria caso se não tivesse verificado a conduta omissiva do Estado-membro faltoso?

Adianta-se uma resposta: é que a norma criadora do direito subjectivo invocado, após o decurso do prazo concedido ao Estado-membro ao qual se dirigia, tornase directamente aplicável. Busca-se assim conseguir uma garantia de efectividade do Direito da União: há situações nas quais só a consagração de um direito de invocação de normas por banda dos sujeitos comunitários particulares assegurará a plena implementação (o máximo efeito útil) do Direito da União (impedindo que os Estados-membros possam bloquear, por oposição ou mera inacção, a normal produção de efeitos das normas comunitárias ${ }^{52}$.

Vale isto dizer que (relativamente às normas incondicionais e suficientemente precisas) o prazo que a directiva assina aos Estados-membros para cumprimento da respectiva obrigação de transposição é assim juridicamente tido para certos propósitos como comportando uma condição suspensiva $a^{53}$, findo cujo prazo aquelas normas passam eventualmente a ter aplicabilidade direct $a^{54}$.

${ }^{52}$ Na doutrina, por todos, HANLON, James. Op. cit., p. 108.

${ }^{53}$ No mesmo sentido, LORENZON, Sara. Op. cit., p. 32-33. Preferimos a nossa qualificação, pois, nestes casos, a aplicabilidade directa virá sempre a ocorrer no fim do aludido prazo, duma maneira ou doutra (vale dizer, independentemente da atitude dos Estados-membros).

${ }^{54} \mathrm{O}$ juiz comunitário já teve oportunidade de clarificar até, quanto às directivas, que "um particu- 
E é precisamente quando (nos termos sobreditos) passam a ter aplicabilidade directa, que elas acabam por poder ser invocadas pelos particulares interessados. Ou, por outras palavras: é por passarem a ter aplicabilidade directa, que passam a ter efeito directo.

Pelo exposto, se vê a nossa discordância com a posição sustentada pela doutrina que defendeu ser "certo que há normas e actos com efeito directo mas sem aplicabilidade directa" ${ }^{n 5}$. Na verdade, cremos que tal tipo de afirmação só poderia ser aceite se com ela se quisesse significar que há normas que vêm a ter efeito directo, não obstante não terem - originariamente - aplicabilidade directa. $\mathrm{Ou}$, explicitando doutro modo: que há normas que, não tendo - pela sua estruturação inicial, pelo teor do acto em que se enquadram - aplicabilidade directa, acabam por vir a ter efeito directo. Ou, dito ainda por outra forma: que há normas que têm efeito directo (subsequente) sem aplicabilidade directa (inicial). Mas, a ser assim, então a asserção em causa estaria empregada em sentido algo translato, fazendo intervir, em aparente papel de concorrentes para a definição de uma dada realidade, duas características que não se verificam em simultâneo (e que, aliás, são forçosamente desfasadas no tempo). Repete-se: somente será aceitável falar-se de efeito directo sem aplicabilidade directa, caso queira significar-se sem aplicabilidade directa anterior.

IV. O que fica dito no ponto antecedente refere-se apenas às normas comunitárias que imponham aos Estados-membros obrigações de facere. Relativamente às normas que estatuam obrigações de abstenção ${ }^{56}$, mais nítidas se tornam ainda as coisas; isto, no caso de obrigações puras, de obrigações não sujeitas a prazo.

Imagine-se então que se está, por exemplo, perante uma directiva contendo normas que impõem aos Estados obrigações puras de abstenção. Pois bem: tais normas terão ab origine, se forem incondicionais e suficientemente precisas, efeito

lar não pode invocar o princípio da 'confiança legítima' antes do fim do prazo previsto para a sua execução" (Ac. TJCE 5 de abril de 1979, Ministério Público / Ratti, 148/78, Rec., pp 1629 ss., c. nº 46, p. 1645).

55 Como já em tempos, p. ex., QUADROS, Fausto de. Direito das Comunidades Europeias e Direito Internacional Público: contributo para o estudo da natureza jurídica do Direito Comunitário Europeu. Lisboa: Almedina, 1991. p. 422, nota 1064.

56 Sobre uma disposição que "enuncia, em termos claros, precisos e incondicionais, uma cláusula inequívoca de 'standstill', que implica uma obrigação assumida pelas Partes Contratantes, que se traduz juridicamente numa simples abstenção" e tem efeito directo, debruça-se, p. ex., o Ac. TJCE 19 de fevereiro de 2009, Mehmet Soysal e o. / Bundesrepublik Deutschland, C-228/06, c. nº 45 (considerando tal característica como"jurisprudência assente"). Disponível em: $<$ http://curia.europa.eu/juris/document/document.jsf?docid $=74024 \&$ mode $=$ req\&pageIndex $=7 \&$ dir $=\&$ occ $=$ first\&part $=1 \&$ text $=\% 2522$ efeito $\% 2 \mathrm{Bdirecto} \% 2522 \&$ doclang=PT\&cid=231496\#ctx1>. Acesso em: 11 jun. 2013. 
directo. Mas isso sucede justamente porque, ab origine, elas têm aplicabilidade directa (embora constantes de um facto normativo, de uma fonte de direito, que, abstractamente considerada, não detém esta característica da aplicabilidade directa $\left.^{57}\right)$. Em casos destes, só esquecendo a própria norma em questão para ter em mente - apenas - o acto (a directiva) onde ela está inserida, se poderia afirmar estarse perante um caso de efeito directo sem aplicabilidade directa. E note-se que, ainda assim, só faria sentido tal afirmação se referida à directiva comunitária como figura abstracta. In concreto, nada se oporá, teoricamente, a que uma directiva tenha aplicabilidade directa (embora não faça muito sentido pois, no rigor dos princípios, não passará de um regulamento "travesti": suponha-se, por exemplo, uma directiva composta exclusivamente por normas que imponham aos Estados obrigações puras de abstenção de certo tipo de novas medidas legislativas ${ }^{58}$ ).

\subsection{A APLICABILIDADE DIRECTA É MAIS AMPLA QUE O EFEITO DIRECTO}

O efeito directo encontra-se dependente de certas características das normas, mas a aplicabilidade directa não está. Desde que as normas se encontrem inseridas em acto dotado de aplicabilidade directa, tê-la-ão ipso jure, mesmo que não revistam as características que lhes confeririam efeito directo. Serão então casos de aplicabilidade directa sem efeito directo.

$\mathrm{O}$ afirmado vale por dizer que a aplicabilidade directa abrange um espaço onde o efeito directo não chega; ora, cobrindo todo o espaço deste e ocupando mais espaço para além do dele, tem aquela por conseguinte maior amplitude ${ }^{59}$.

${ }^{57}$ Sublinhe-se que isto vale mesmo para o Tratado Institutivo. Parece-nos paradigmático o que pode ler-se logo no célebre Ac. Costa / ENEL, do qual consta que "o artigo $37^{\circ}, \mathrm{n}^{\circ} 2$ [do Tratado CEE], enuncia uma proibição incondicional que não constitui uma obrigação de facere, mas sim de non facere; [...] esta obrigação não contém nenhuma reserva que subordine a sua eficácia a um acto positivo de direito interno; [...] esta proibição, pela sua própria natureza, é susceptível de produzir efeitos directos nas relações jurídicas entre os Estados-membros e os seus nacionais; [...] uma proibição assim formalmente expressa, entrada em vigor com o Tratado em toda a Comunidade e, por tal facto, integrada no sistema jurídico dos Estadosmembros, constitui a própria lei destes e diz directamente respeito aos seus nacionais em proveito dos quais atribuiu direitos individuais que os órgãos jurisdicionais nacionais devem salvaguardar" (Ac. TJCE 15 de julho de 1964, 6/64, Rec., p. 1141 ss., p. 1164).

${ }^{58}$ Sobre as directivas tão "detalhadas ou particularizadas" que configuram, em substância regulamentos, por todos, na doutrina, ZANGHÌ, Claudio. Op. cit., p. 282; veja-se, mais latamente, também p. 284.

59 Como expressiva ilustração doutrinária, que inteiramente subscrevemos, para este ponto, pode ler-se que "o facto de uma norma não gozar na prática de efeito directo, e portanto não poder ser directamente invocável em tribunal ou não poder ser levada em conta por este, em virtude de não ser 'incondicional, suficientemente clara, e completa em si mesmo' (as três condições de que no caso Van Gend o TC fez depen- 
I. Cremos haver essencialmente dois tipos de argumentação que podem tentar aduzir-se para contrariar o entendimento que sustentamos.

De uma banda, dizer-se que tal entendimento esqueceria a circunstância de (e tomando agora as directivas por paradigma) a indevida não transposição de uma directiva, constituindo incumprimento de obrigação comunitária, jamais poderia conduzir a um resultado final igual ao que, caso operada aquela transposição, se verificaria.

De outra banda, afirmar-se que o efeito directo teria de constituir forçosamente algo de inferior à aplicabilidade directa, dado ser tão-somente garantido por via judicial.

II. Passaremos já de seguida ao ataque da primeira objecção, continuando a recorrer ao paradigma da directiva. $\mathrm{E}$ diremos que o haver incumprimento de obrigação pelos Estados-membros, por não transposição de directivas, mesmo nos casos em que estas tenham efeito directo ${ }^{60}$, não implica que nestes casos inexista aplicabilidade directa. Nos casos de não transposição ilícita, os Estados-membros estarão certamente em falta, pois não realizaram o Direito pela forma que o legislador da União pretendia em primeira linha, e natural é que se procure compeli-los a fazêlo. Com efeito, é uma situação indesejável, além do mais pelas incertezas que pode gerar (argumento que tem sido brandido, embora o tenhamos por meramente factual, não jurídico ${ }^{61}$ ). Mas a norma comunitária, se revestir as características de precisão e incondicionalidade, não fica dependente daquele inadimplemento para

der o efeito directo de uma norma do Tratado), não prejudica, só por si, a sua aplicabilidade directa, se o art. $189^{\circ}$ lha atribuir, isto é, não impede a sua vigência imediata na ordem interna, independentemente dos critérios para o efeito definidos no Direito interno" (Quadros, Fausto de. Op. cit., p. 422, nota 1064). Mais recentemente, FAIRHURST, John; VINCENZI, Christopher. Op. cit., p. 190-191.

${ }^{60}$ Embora seja quase ocioso sublinhá-lo, "a concretização da infracção não depende da produção do efeito directo da disposição infringida", como por exemplo lembrou SILVA, Karine de Souza. El cumplimiento del Derecho Comunitario por los Estados Miembros de la Unión Europea: alcances y limítes de la acción por incumplimiento. Jean Monnet/Robert Schuman Paper Series, october 2009, v. 9, n. 9, p. 5. Disponível em: <http://aei.pitt.edu/14997/1/SilvaSpanLawLong09Edi.pdf>. Acesso em: 24 maio 2013.

${ }^{61} \mathrm{O}$ Tribunal de Justiça não se coibiu de insistir em esgrimir com o argumento, apesar de referir expressis verbis tratar-se de uma realidade factual. Veja-se, quanto à situação (paralela) da manutenção, por um Estado-membro, de um texto legislativo incompatível com uma disposição do Tratado CEE, apesar do efeito directo desta, o Ac. Comissão / Itália, de 15 de outubro de 1986, em cujo c. no 11 se alude a "situação factual ambígua, já que mantém os sujeitos de direito interessados num estado de incerteza quanto às possibilidades que lhe estão reservadas de recorrer ao direito comunitário" (168/85, Col., p. 2945 ss., p. 2960). De "situação de facto ambígua" fala também, num tempo próximo, o Ac. TJCE 24 de Março de 1988, Comissão / Itália, 104/86, Col., p. 1799 ss., c. nº 12, p. 1817. 
entrar de pleno a ser lei no Estado faltoso. A norma comunitária vale a se, e é Direito plenamente pertencente à Ordem Jurídica do Estado faltoso, nem que depare com a oposição deste ao cumprimento da sua obrigação comunitária de transposição da respectiva directiva continente.

Reconhecemos, sem embargo, que a admissibilidade da figura do efeito directo ("descoberta" ou "induzida", pelo Tribunal de Justiça, a partir duma perspectiva da ratio ou finalidade profunda do Direito Comunitário, com a maximização do efeito útil deste ${ }^{62}$ ) não foi isenta de reparos e de críticas.

Houve (e continua a haver) quem objectasse existirem valores de igual dignidade a salvaguardar, os quais seriam postos em causa com a consagração do efeito directo; pelo que o efeito das normas do Direito Comunitário deveria ser assegurado através dos mecanismos expressamente previstos no Tratado, e não através da consagração da possibilidade de "passar por cima" de actos que, apesar de devidos, não tivessem sido praticados. Assim, também seria necessário, por exemplo, salvaguardar o efeito útil da própria disposição do Tratado consagradora da figura das directivas (se o Tratado confere aos Estados a competência para transpor as directivas, estar-se-ia afinal, ao permitir-se que um particular se prevaleça de uma directiva não transposta, a negar o efeito útil daquela disposição). De resto, a obrigação de transposição das directivas tem um asseguramento expresso no Tratado (a acção por incumprimento); quanto a este ponto, e um pouco mais em detalhe, dir-se-ia que, se um Estado incumpre, não transpondo uma directiva que devia transpor, há para isso remédio no Tratado (a acção por incumprimento), pelo que não haveria razão para se "fabricar" um meio alternativo (a atribuição de efeito directo às disposições da directiva não transposta).

Não falta porém abalizada doutrina a subscrever a figura do efeito directo, aduzindo aliás a argumentação veiculada pela jurisprudência comunitária. ${ }^{63}$

Da nossa parte, e pelo que nomeadamente respeita ao aduzido considerando da acção por incumprimento, parece-nos que o caminho percorrido pelo Tribunal levou a um resultado aceitável, ou pelo menos compreensível, porque a acção por incumprimento, operando a nível exclusivamente internacional, pode não garantir, por si só, a plenitude da aplicação das normas duma directiva indevidamente não transposta ${ }^{64}$.

III. Quanto à segunda objecção, consignamos que o facto de o efeito directo apenas ser juridicamente garantido por via judicial, não significa uma natureza jurídica diferente, designadamente inferior, das normas que o têm. Neste âmbito é de ponderar,

\footnotetext{
${ }^{62}$ Aludindo a esta maximização, na doutrina, por todos, MENGOZZI, Paolo. Op. cit., p. 154.

${ }_{63}$ Para um condensado panorama sobre esta controvérsia, LORENZON, Sara. Op. cit., p. 30.

${ }^{64}$ Na mesma linha, por todos, HANLON, James. Op. cit., p. 108.
} 
desde logo, que a via judicial é a garante normal de ultima ratio relativamente a todo o Direito. E sublinhe-se que falamos aqui intencionalmente de garantia: é que teremos ocasião, um pouco mais abaixo, de ver como os direitos exclusivamente assegurados pelo efeito directo podem não necessitar da mediação do tribunal. Seja como for, e no tocante à garantia constituída pela tutela judicial, há que sublinhar que todos os direitos subjectivos a têm como garantia última. $\mathrm{O}$ acautelamento último dos direitos subjectivos, quer contra agressões dos particulares, quer contra agressões do próprio Poder, está integralmente confiado aos tribunais (ao menos no Estado de Direito democrático-ocidental; e isso nos basta, já que a União Europeia é hoc sensu uma União de Direito, como é pacificamente reconhecido). Conseguintemente, e sob este prisma, os direitos exclusivamente assegurados pelo efeito directo em nada diferem de qualquer outro direito subjectivo.

Para além do ora exposto, a figura dos direitos de exercício judicial obrigatório, indiscutivelmente jurídica "de pleno", émais estreita do que a dos direitos exclusivamente assegurados pela via do efeito directo. E, ao chamarmos à colação, em derradeiro lugar, a figura dos direitos de exercício judicial obrigatório, o nosso propósito é afastar, com uma argumentação ad abundantiam, as observações contrárias ao nosso pensamento. Isto, porque esta última figura, cuja "plena juridicidade" é incontestável, tem afinal, como de seguida demonstraremos, um alcance jurídico mais restrito do que a dos direitos exclusivamente assegurados pelo efeito directo.

Assim, e logo à cabeça, refira-se que os direitos exclusivamente assegurados pelo efeito directo podem não necessitar da mediação do tribunal; com efeito, os direitos subjectivos não podem ser exclusivamente analisados na óptica da sua violação, o que seria mutilar a realidade: a experiência da vivência jurídica das sociedades revela-nos, ao invés, que a grande maioria dos direitos subjectivos é exercida pelos respectivos titulares sem que lhes seja posto embaraço a tal (a violação daqueles é uma patologia, comparativamente rara em confronto com o decurso normal da vida jurídica). Ora, diferentemente do que sucede com os direitos de exercício judicial obrigatório, e tal como acontece com a generalidade dos direitos subjectivos, os direitos exclusivamente assegurados pelo efeito directo têm vocação para ser exercidos sem necessidade de intervenção do tribunal ${ }^{65}$; têm pois, neste aspecto, maior amplitude jurídica: desde que os demais sujeitos de Direito os respeitem, em nada necessitam da intervenção dos órgãos jurisdicionais.

65 Veja-se, p. ex., a elucidativa afirmação, do Tribunal de Justiça, de que "preenchidas as condições exigidas pela jurisprudência do tribunal para as normas de uma directiva poderem ser invocadas pelos particulares perante os tribunais nacionais, todos os órgãos da administração, incluindo as entidades descentralizadas, tais como as comunas, têm o dever de aplicar aquelas disposições" (Ac. TJCE 22 de junho de 1989, Fratelli Costanzo / Comuna de Milão, 103/88, cit., c. nº 31, p. 1871). 
Ademais, completando o parágrafo anterior, deve assinalar-se que os direitos exclusivamente assegurados pelo efeito directo têm uma dupla tutela judicial: a directa (via tribunais nacionais) e a indirecta (via tribunais da União). Dissemos, um pouco acima, que optaríamos por uma demonstração ad abundantiam da nossa tese, e daí o presente fecho; efectivamente, depois da comparação que oportunamente fizemos (salientando que os direitos exclusivamente assegurados pelo efeito directo podem não necessitar da mediação do tribunal), encerramos com outra que, por via diversa, nos leva igualmente à conclusão de que a figura dos direitos exclusivamente assegurados pelo efeito directo não fica a perder no cotejo com a dos direitos de exercício judicial obrigatório (ficando aliás a ganhar, como se sublinhará no remate do texto, sempre que os direitos de exercício judicial obrigatório se fundem apenas no Direito Interno). Na exposição que antecedeu, quisemos deslocar o debate da área estreita da garantia judicial, tendo explicado o porquê; mas para reforço de argumentos voltamos ainda àquela, aduzindo a circunstância de que os direitos exclusivamente assegurados pelo efeito directo são afinal tão "jurídicos", que têm a característica de gozar de uma dupla tutela judicial: em via directa, junto dos tribunais nacionais, adstritos a reconhecê-los e dar-lhes plena e total garantia; e em via indirecta, junto dos tribunais da União, quer mediante o accionamento do mecanismo prejudicial do artigo $267^{\circ}$, do TFUE, quer mediante a acção por incumprimento dos artigos $258^{\circ}$ a $260^{\circ}$, do TFUE, já que fundados por definição no Direito da União.

\section{CONCLUSÕES}

a) O efeito directo é a característica, de certas disposições do Direito da União Europeia, de constituírem base válida para atribuir aos particulares direitos que estes podem invocar perante os órgãos jurisdicionais nacionais.

b) A aplicabilidade directa é a característica, de dadas disposições do Direito da União Europeia, de entrarem só por si a fazer parte da Ordem Jurídica dos Estados-membros, atribuindo e impondo direitos e deveres aos destinatários.

c) $\mathrm{O}$ efeito directo assenta nos mesmos fundamentos de substância que a aplicabilidade directa.

d) Por outro lado, o efeito directo tem a mesma natureza substancial que a aplicabilidade directa.

e) Trata-se, no entanto, de figuras jurídicas diferentes, dado terem uma amplitude diversa. 
f) Mais precisamente, a figura da aplicabilidade directa engloba a figura do efeito directo, não se circunscrevendo porém a este.

g) Dito de outro modo, todas as normas detentoras de efeito directo têm ipso facto aplicabilidade directa; mas existem normas, dotadas de aplicabilidade directa, que carecem todavia de efeito directo.

h) $\mathrm{O}$ efeito directo corporiza uma inferência jurisprudencial de cariz intrinsecamente lógico, que dalgum modo maximiza o alcance normativo útil de certas disposições do Direito da União Europeia.

i) Dum ponto de vista de conjunto, importa todavia reconhecer que toda esta questão é extremamente melindrosa, já que, na base duma análise jurídica considerada válida, tem de jazer inevitavelmente o correcto equacionamento de duas magnas variáveis.

j) Efectivamente, perfila-se, duma banda, a necesssidade dum robusto manejo da delicada problemática (jurídica, genérica e básica) do papel da jurisprudência no conspecto das fontes do Direito.

k) Impõe-se, doutra banda, o imperativo da descoberta da adequada concepção política de fundo sobre o verdadeiro papel dos Estadosmembros no contexto da construção da União Europeia, entidade esta cujo pioneirismo e cuja plasticidade de contornos se não deixam aprisionar nas malhas dum esquema jurídico indubitável e inquestionável.

\section{JURISPRUDÊNCIA CITADA (CLÁSSICA — ANTERIOR A 2000)}

Administração das Finanças do Estado / Essevi e Salengo (Ac. TJCE 27 de maio de 1981, 142 e 143/80, Rec., p. 1413 ss.)

Administração das Finanças do Estado / Simmenthal (Ac. TJCE 9 de março de 1978, 106/77, Rec., p. 629 ss.)

Bussone / Ministério Italiano da Agricultura (Ac. TJCE 30 de novembro de 1978, 31/78, Rec., p. 2429 ss.)

Comissão / Itália (Ac. TJCE 15 de outubro de 1986, 168/85, Col., p. 2945 ss.)

Comissão / Itália (Ac. TJCE 24 de Março de 1988, 104/86, Col., p. 1799 ss.)

Comissão / Itália (Ac. TJCE 26 de fevereiro de 1991, C-120/88, Col., p. I-621 ss.)

Comissão / Itália (Ac. TJCE 28 de março de 1985, 272/83, Rec., p. 1057 ss.)

Costa / ENEL (Ac. TJCE 15 de julho de 1964, 6/64, Rec., p. 1141 ss.)

Delimitis (Ac. TJCE 28 de fevereiro de 1991, C-234/89, Col., p. I-935 ss.)

Donà / Mantero (Ac. TJCE 14 de julho de 1976, 13/76, Rec.,p. 1333 ss.)

Fink-Frucht (Ac. TJCE 4 de abril de 1968, 27/67, Rec., p. 327 ss.) 
Foster e outras (Ac. TJCE 12 de julho de 1990, C-188/89, Col., p. I-3313 ss.)

Fratelli Costanzo / Comuna de Milão (Ac. TJCE 22 de junho de 1989, 103/88, Col., p. 1839 ss.)

Grad / Finanzamt Traunstein (Ac. TJCE 6 de outubro de 1970, 9/70, Rec., p. 825 ss.)

Kaefer e Procacci (Ac. TJCE 12 de dezembro de 1990, C-100/89 e C-101/89, Col., p. I-4647 ss.)

Karella e Karellas (Ac. TJCE 30 de maio de 1991, C-19/90 e C-20/90, Col., p. I-2691 ss.)

Kühne / Finanzamt München III (Ac. TJCE 27 de junho de 1989, 50/88, Col., p. 1925 ss.)

Leonesio / Ministério italiano da Agricultura (Ac. TJCE 17 de maio de 1972, 93/71, Rec., p. 287 ss.)

Marty / Lauder (Ac. TJCE 10 de julho de 1980, 37/79, Rec., p. 2481 ss.)

Ministério Público / Ratti (Ac. TJCE 5 de abril de 1979, 148/78, Rec., p. 1629 ss.)

Ministério Público luxemburguês / Muller (Ac. TJCE 14 de julho de 1971, 10/71, Rec., p. 723 ss.)

Molkerei-Zentrale (Ac. TJCE 3 de abril de 1968, 28/67, Rec., p. 211 ss.)

Nimz (Ac. TJCE 7 de fevereiro de 1991, C-184/89, Col., p. I-297 ss.)

Oberkreisdirektor des Kreises Borken e outros / Moormann (Ac. TJCE 20 de setembro de 1988, 190/87, Col., p. 4689 ss.)

Pigs Marketing Board / Redmond (Ac. TJCE 29 de novembro de 1978, 83/78, Rec., p. 2347 ss.)

Sacchi (Ac. TJCE 30 de abril de 1974, 155/73, Rec., p. 409 ss.)

Verholen e outros (Ac. TJCE 11 de julho de 1991, C-87/90, C-88/90 e C-89/90, Col., p. I-3757 ss.)

Watson e Belmann (Ac. TJCE 7 de julho de 1976, 118/75, Rec., p. 1185 ss.)

Zerbone / Amministrazione delle finanze dello Stato (Ac. TJCE 31 de janeiro de 1978, 94/77, Rec., p. 99 ss.)

\section{JURISPRUDÊNCIA CITADA (ACTUAL — POSTERIOR A 2000)}

Asociación Nacional de Establecimientos Financieros de Crédito (ASNEF) e o. / Administración del Estado (Ac. TJUE 24 de novembro de 2011, C-468/10 e C-469/10. Disponível em: <http:// curia.europa.eu/juris/document/document.jsf ?docid $=115205 \&$ mode $=$ req\&pageIndex $=1 \&$ $\operatorname{dir}=$ \&occ $=$ first\&part $=1 \&$ text $=\% 2522$ efeito $\% 2$ Bdirecto $\% 2522 \&$ doclang $=$ PT\&cid $=80820 \#$ ctxl>. Acesso em: 10 jun. 2013.

Commissioners for Her Majesty's Revenue and Customs / The Rank Group plc (Ac. TJUE 10 de novembro de 2011, C-259/10 e C-260/1. Disponível em: <http://curia.europa.eu/juris/ document $/$ document.jsf ?docid $=113588 \&$ mode $=$ req\&pageIndex $=1 \&$ dir $=\& o c c=$ first $\&$ part $=1 \&$ text $=\% 2522$ efeito $\% 2 B$ directo $\% 2522 \&$ doclang $=P T \& c i d=190338 \#$ ctxl $>$. Acesso em: 11 jun. 2013.

Tural Oguz / Secretary of State for the Home Department (Ac. TJUE 21 de julho de 2011, C-186/10. Disponível em: <http://curia.europa.eu/juris/document/document.jsf?docid=107930\&mode $=$ req\&pageIndex $=1 \&$ dir $=\& o c c=$ first $\&$ part $=1 \&$ text $=\% 2522$ efeito $\% 2$ Bdirecto $\% 2522 \&$ doclang =PT\&cid=206561\#ctxl>. Acesso em: 11 jun. 2013.

Rosa María Gavieiro Gavieiro e o. / Consellería de Educación e Ordenación Universitaria de la Xunta de Galicia (Ac. TJUE 22 de dezembro de 2010, C-444/09 e C-456/09. Disponível em: $<$ http://curia.europa.eu/juris/document/document.jsf ?docid $=83450 \&$ mode $=$ req\&pageIndex $=2 \&$ dir $=\&$ occ $=$ first \& part $=1 \&$ text $=\% 2522$ efeito $\% 2$ Bdirecto $\% 2522 \&$ doclang $=$ PT\&cid=206561\#ctxl>. Acesso em: 11 jun. 2013. 
Günter Fuß / Stadt Halle (Ac. TJUE 25 de novembro de 2010, C-429/09. Disponível em: < http:// curia.europa.eu/juris/document/document.jsf ?doclang $=\mathrm{PT} \&$ text $=\% 2522 \mathrm{efeito} \% 2 \mathrm{Bdirecto}$ $\% 2522 \&$ pageIndex $=3 \&$ docid $=79740 \&$ mode $=$ req \& part $=1 \&$ occ $=$ first $\&$ dir $=\&$ cid $=206561 \#$ ctx1>. Acesso em: 11 jun. 2013.

Maurits Casteels / British Airways plc (Ac. TJUE 10 de março de 2011, C-379/09. Disponível em: <http://curia.europa.eu/juris/document/document.jsf?docid=80426\&mode=req\&page Index $=3 \&$ dir $=\&$ occ $=$ first $\&$ part $=1 \&$ text $=\% 2522$ efeito $\% 2$ Bdirecto $\% 2522 \&$ doclang $=$ PT\&cid =206561\#ctxl>. Acesso em: 11 jun. 2013.

Günter Fuß / Stadt Halle (Ac. TJUE 14 de outubro de 2010, C-243/09. Disponível em: <http:// curia.europa.eu/juris/document/document.jsf ?docid $=82939 \&$ mode $=$ req $\&$ pageIndex $=3 \&$ dir $=\&$ occ $=$ first $\&$ part $=1 \&$ text $=\% 2522$ efeito $\% 2$ Bdirecto $\% 2522 \&$ doclang $=$ PT\&cid $=206561 \#$ ctx1>. Acesso em: 11 jun. 2013.

Belgische Staat / Direct Parcel Distribution Belgium NV (Ac. TJUE 28 de janeiro de 2010, C-264/08. Disponível em: <http://curia.europa.eu/juris/document/document.jsf?docid $=72516 \&$ mode $=$ req $\&$ pageIndex $=5 \&$ dir $=\& o c c=$ first $\&$ part $=1 \&$ text $=\% 2522$ efeito $\% 2$ Bdirecto $\% 2522 \&$ doclang=PT\&cid=214756\#ctxl $>$. Acesso em: 11 jun. 2013.

Susanne Gassmayr / Bundesminister für Wissenschaft und Forschung (Ac. TJUE 1 de julho de 2010, C-194/08. Disponível em: <http://curia.europa.eu/juris/document/document.jsf?docid $=79081 \&$ mode $=$ req $\&$ pageIndex $=5 \&$ dir $=\&$ occ $=$ first $\&$ part $=1 \&$ text $=\% 2522$ efeito $\% 2$ Bdirecto $\% 2522 \&$ doclang=PT\&cid=214756\#ctxl>. Acesso em: 11 jun. 2013.

Mehmet Soysal e o. / Bundesrepublik Deutschland (Ac. TJCE 19 de fevereiro de 2009, C-228/06. Disponível em: $<$ http://curia.europa.eu/juris/document/document.jsf ?docid $=74024 \&$ mode $=$ req \&pageIndex $=7 \&$ dir $=\& o c c=$ first $\&$ part $=1 \&$ text $=\% 2522$ efeito $\% 2$ Bdirecto $\% 2522 \&$ doclang $=$ PT\&cid=231496\#ctxl>. Acesso em: 11 jun. 2013.

Winner Wetten GmbH / Bürgermeisterin der Stadt Bergheim (Ac. TJCE 8 de setembro de 2010, C-409/06. Disponível em: <http://curia.europa.eu/juris/document/document.jsf?docid $=80771 \&$ mode $=$ req \&pageIndex $=8 \&$ dir $=\&$ occ $=$ first $\&$ part $=1 \&$ text $=\% 2522$ efeito $\% 2$ Bdirecto $\% 2522 \&$ doclang=PT\&cid=234323\#ctxl>. Acesso em: 11 jun. 2013.

Bureau national interprofessionnel du Cognac (Ac. TJUE 14 de julho de 2011, C-4/10 e C-27/10. Disponível em: <http://curia.europa.eu/juris/document/document.jsf?docid=107353\&mode $=$ req \& pageIndex $=1 \& \operatorname{dir}=\& o c c=$ first $\&$ part $=1 \&$ text $=\% 2522$ aplicabilidade $\% 2 \mathrm{Bdirecta}$ $\% 2522 \&$ doclang=PT\&cid=291980\#ctxl>. Acesso em: 12 jun. 2013.

Götz Leffler / Berlin Chemie AG (Ac. TJCE 8 de novembro de 2005, C-443/03Disponível em: $<$ http://curia.europa.eu/juris/document/document.jsf ?docid $=55594 \&$ mode $=$ req\&pageIndex $=1 \&$ dir $=\&$ occ $=$ first $\&$ part $=1 \&$ text $=\% 2522$ aplicabilidade $\% 2$ Bdirecta $\% 2522 \&$ doclang $=$ PT $\&$ cid=230961\#ctxl>. Acesso em: 12 jun. 2013.

Jürgen Römer / Freie und Hansestadt Hamburg (Ac. TJUE 10 de maio de 2011, C-147/08. Disponível em: <http://curia.europa.eu/juris/document/document.jsf?docid=80921\&mode=req \&pageIndex $=3 \&$ dir $=\&$ occ $=$ first \&part $=1 \&$ text $=\% 2522$ directamente $\% 2 \mathrm{Baplic} \% 25 \mathrm{C} 3 \% 25 \mathrm{~A}$ lvel\%2522\&doclang=PT\&cid=314174\#ctx $>$. Acesso em: 12 jun. 2013.

Sophiane Gysen / Groupe S-Caisse d'Assurances sociales pour indépendants (Ac. TJCE 14 de fevereiro de 2008, C-449/06. Disponível em: <http://curia.europa.eu/juris/document/document. $\mathrm{jsf}$ ? docid $=71572 \&$ mode $=$ req\&pageIndex $=4 \& \operatorname{dir}=\&$ occ $=$ first $\&$ part $=1 \&$ text $=\% 2522$ directa mente \%2Baplic\%25C3\%25Alvel\%2522\&doclang=PT\&cid=258523\#ctxl>. Acesso em: 12 jun. 2013. 
Laval un Partneri Ltd / Svenska Byggnadsarbetareförbundet e o. (Ac. TJCE 18 de dezembro de 2007, C-341/05. Disponível em: <http://curia.europa.eu/juris/document/document.jsf?text=\% 2522 directamente \% 2 Baplic \% 25 C3\%25 A 1 vel \% 2522\&docid $=71925 \&$ pageIndex $=0 \&$ doclang $=$ pt\&mode $=$ req\&dir $=\& o c c=$ first\&part $=1 \&$ cid=408822\#ctxl $>$. Acesso em: 13 jun. 2013.

Meiland Azewijn BV/ Hauptzollamt Duisburg (Ac. TJCE 9 de setembro de 2004, C-292/02 Disponível em: $<$ http://curia.europa.eu/juris/document/document.jsf?docid $=49469 \& \operatorname{mode}=$ req \&pageIndex $=6 \& \operatorname{dir}=\& o c c=$ first \&part $=1 \&$ text $=\% 2522$ directamente $\% 2 \mathrm{Baplic} \% 25 \mathrm{C} 3 \% 25 \mathrm{~A}$ lvel\%2522\&doclang=PT\&cid=420429\#ctxl>. Acesso em: 13 jun. 2013.

Herbert Handlbauer GmbH (Ac. TJCE 24 de junho de 2004, C-278/02Disponível em: <http:// curia.europa.eu/juris/document $/$ document.jsf $?$ docid $=49312 \&$ mode $=$ req $\&$ pageIndex $=6 \&$ dir $=\&$ occ $=$ first \&part $=1 \&$ text $=\% 2522$ directamente $\% 2$ Baplic $\% 25 \mathrm{C} 3 \% 25 \mathrm{Al}$ vel $\% 2522 \&$ doclang $=$ PT\&cid=420429\#ctxl>. Acesso em: 13 jun. 2013.

Comissão / Bélgica (Ac. TJCE 3 de dezembro de 2009, C-475/08. Disponível em: <http:// curia.europa.eu/juris/document $/$ document.jsf ?docid $=73874 \&$ mode $=$ req \&pageIndex $=1 \&$ dir $=\&$ occ $=$ first $\&$ part $=1 \&$ text $=\% 2522$ aplicabilidade $\% 2$ Bdirecta $\% 2522 \&$ doclang $=\mathrm{PT} \& c i d$ $=295740 \#$ ctxl $>$. Acesso em: 12 jun. 2013.

Comissão / França (Ac. TJUE 5 de outubro de 2010, C-512/08. Disponível em: <http://curia. europa.eu/juris/document/document.jsf ?docid $=81397 \&$ mode $=$ req\&pageIndex $=2 \& d i r=\& o c c=$ first\&part $=1 \&$ text $=\% 2522$ directamente $\% 2$ Baplic $\% 25 \mathrm{C} 3 \% 25 \mathrm{Al}$ vel $\% 2522 \&$ doclang $=$ PT\&cid =314174\#ctxl>. Acesso em: 12 jun. 2013.

Richard Dahms GmbH / Fränkischer Weinbauverband eV (Ac. TJCE 13 de outubro de 2005, C-379/04. Acesso em: <http://curia.europa.eu/juris/document/document.jsf?docid=60257\& mode $=$ req\&pageIndex $=5 \&$ dir $=\& o c c=$ first $\&$ part $=1 \&$ text $=\% 2522$ directamente $\% 2$ Baplic $\%$ 25C3\%25Alvel\%2522\&doclang=PT\&cid=408822\#ctxl>. Acesso em: 13 jun. 2013.

Murat Dereci e o. / Bundesministerium für Inneres (Ac. TJUE 15 de novembro de 2011, C-256/11. Disponível em: <http://curia.europa.eu/juris/document/document.jsf?docid=114222\&mo $\mathrm{de}=$ req\&pageIndex $=1 \&$ dir $=$ \&occ $=$ first $\&$ part $=1 \&$ text $=\% 2522$ efeito $\% 2$ Bdirecto $\% 2522 \&$ do clang $=$ PT\&cid=190338\#ctx1>. Acesso em: 11 jun. 2013.

\section{REFERÊNCIAS}

BIN, Roberto. Nota brevissima su uno strano caso di disapplicazione della legge tributaria a danno del privato, per contrasto con una direttiva europea, 12 luglio 2012. Disponível em $<$ http://www.fo rumcostituzionale.it/site/images/stories/pdf/documenti_forum/giurisprudenza/giurisdizioni_or dinarie/0012_bin.pdf $>$. Acesso em: 27 maio 2013.

BONGIOVANNI, Veronica. Riflessi privatistici in materia contrattuale del principio comunitario di non discriminazione. Comparazione e Diritto Civile, dicembre 2010. Disponível em: $<$ http://www.comparazionedirittocivile.it/prova/files/buongiovanni_riflessi.pdf $>$. Acesso em: 27 maio 2013.

CICCI S., Gilda. La responsabilidad del Estado por violación del derecho comunitario: jurisprudencia del Tribunal de Justicia. Ars Boni et Aequi: Revista Jurídica de la Universidad Bernardo O'Higgins, enero 2010, año 6, n. 1, p. 9-25

CRAIG, Paul. The legal effect of directives: policy, rules and exceptions. University of Oxford Legal Research Paper Series, august 2009, n. 24, p. 349-377. Disponível em: <http://papers.ssrn. com/sol3/papers.cfm?abstract_id=1433782>. Acesso em: 24 maio 2013. 
DE MOL, Mirjam. The novel approach of the CJEU on the horizontal direct effect of the EU principle of non-discrimination: (unbridled) expansionism of EU Law? Maastricht Journal of European and Comparative Law, 2011, v. 18, n. 1, p. 109-135.

FAIRHURST, John; VINCENZI, Christopher. Law of the European Community. 4. ed. Harlow: Longman, 2003.

FERREIRA, Eduardo Paz. Sessão de abertura da Pós-Graduação em Jurisprudência da União Europeia 2010-1011. In FERREIRA, E. P. (Org.). Justiça Nacional, Justiça Europeia: a jurisprudência do Tribunal de Justiça da União Europeia Coimbra: Almedina, 2011. p. 5-15.

FRANCK, Gunnar. Die horizontale unmittelbare Anwendbarkeit der EG-Grundfreiheiten: Grundlagen und aktuelle Entwicklung. Beiträge zum Europa - und Völkerrecht, januar 2009, heft 1. Disponível em: <http://telc.jura.uni-halle.de/sites/default/files/telc/Heftl.pdf>. Acesso em: 26 maio 2013.

GASPAR, António Henriques. O Direito Europeu em acção: a jurisprudência do Tribunal de Justiça da União Europeia. In: FERREIRA, E. P. (Org.). Justiça Nacional, Justiça Europeia: a Jurisprudência do Tribunal de Justiça da União Europeia. Coimbra: Almedina, 2011. p. 37-52.

GROUSSOT, Xavier; Pech, Laurent. La protection des droits fondamentaux dans l'Union européenne après le Traité de Lisbonne. Questions d'Europe (Fondation Robert Schuman), n. 173, 14 juin 2010. Disponível em: <http://www.robert-schuman.eu/doc/questions_europe/qe-173-fr. pdf>. Acesso em: 9 mar. 2011.

HANLON, James: European Community Law. 3. ed. London: Sweet \& Maxwell, 2003.

JANS, Jan H. European environmental Law before Dutch Courts: observations on direct effect and consistent interpretation, december 9, 2011. Disponível em: <http://ssrn.com/abstract $=1970270>$. Acesso em: 24 maio 2013 .

KESSEBOHM, Ricarda. Das Gemeinschaftsrecht im englischen Recht. Seminararbeit im Gebiet Die Stellung von Europa - und Völkerrecht im nationalen Recht, unter der Leitung von Prof. Dr. Mahulena Hofmann, Justus-Liebig-Universität Gießen, 2007. Disponível em: <http://www. recht.uni-giessen.de/wps/fb01/dl/down/open/hofmann/6d14a0c6914398874529d82a9b17092 cf5bd649cfc8d76802c192522d4658b82a6341f956822d75bea3cb411ec01c524/EG_Recht_in_ Gro_britannien.pdf>. Acesso em: 26 maio 2013.

LOPES, Dulce. Principais contributos da União Europeia e do Conselho da Europa em matéria de não discriminação. Debater a Europa, jan.-jun. 2011, n. 4, p. 32-61. Disponível em: <http://eu rope-direct-aveiro.aeva.eu/debatereuropa/images/n4/principais.pdf>. Acesso em: 23 maio 2013.

LÓPEZ DE LOS MOZOS DÍAZ-MADROÑERO, Alicia. La normativización de la jurisprudencia del Tribunal de Justicia de las Comunidades Europeas. Revista General de Derecho Público Comparado, 2008, n. 3, p. 1-17. Disponível em: <http://www.iustel.com>. Acesso em: 23 maio 2013.

LORENZON, Sara. Teoria degli effetti diretti e applicazione del diritto: L'efficacia delle norme self-executing nell'nterpretazione della corte di giustizia e del giudice interno. Tese de doutoramento, Università degli Studi di Ferrara, Annali online: Pubblicazioni dello IUSS, 2008, v. 2, n 1. Disponível em: <http://annali.unife.it/iuss/article/download/328/281>. Acesso em: 24 maio 2013.

MARTÍNEZ CAPDEVILA, Carmen. Otra virtualidad de las directivas: su "efecto directo de exclusión" Revista electrónica de estudios internacionales, diciembre 2006, n. 12. Disponível em: <http://www.reei.org/index.php/revista/num12/archivos/MtnezCapdevila(reeil2).pdf>. Acesso em: 23 maio 2013. 
MENGOZZI, Paolo. Istituzioni di diritto comunitario e dell'Unione europea. Padova: CEDAM, 2003.

MIRAGLIA, Michele. La responsabilità dello Stato per violazione del diritto dell'Unione europea da parte dell'organo giurisdizionale: la cronaca di una morte annunciata. Amministrazione in Cammino, febbraio 2012. Disponível em: <http://www.amministrazioneincammino.luiss. it/?p=17485>. Acesso em: 27 maio 2013.

PACE, Alessandro. La sentenza granital, ventitrè anni dopo. Studi sull'integrazione europea, 2007 , v. 2 , fasc. 3 , p. $451-467$.

QUADROS, Fausto de. Direito das Comunidades Europeias e Direito Internacional Público: contributo para o estudo da natureza jurídica do Direito Comunitário Europeu. Lisboa: Almedina, 1991.

RACCAH, Aurélien. L'accès aux normes de l'Union, composante de leur application directe. Jurisdoctoria, octobre 2008, n. 1, p. 91-116. Disponível em: <http://www.jurisdoctoria.net/pdf/ numerol/NUMERO_1.pdf>.Acesso em: 24 maio 2013.

RACCAH, Aurélien. Les effets de l'application directe du Droit de l'Union par les autorités régionales et locales européennes sur l'Ordonnancement Juridique des États Membres: les exemples allemand, britannique et français. European Journal of Legal Studies, 2008, v. 2, n. 1, p. 269-285. Disponível em: <http://www.ejls.eu/4/59FR.pdf>. Acesso em: 24 maio 2013.

RODER, Thomas. Die horizontale Wirkung nicht umgesetzter EG-Richtlinien. Dissertation zur Erlangung des akademischen Grades doctor juris (Dr. iur.) vorgelegt dem Fakultätsrat der Rechtswissenschaftlichen Fakultät der Friedrich-Schiller-Universität Jena, 2007. Disponível em: <http://www.db-thueringen.de/servlets/DerivateServlet/Derivate-13306/Dissertation \%20 Thomas\%20Roder.pdf $>$. Acesso em: 26 maio 2013.

RODRIGUES, José Narciso Cunha. Alguns Temas e Múltiplos Desafios. In: FERREIRA, E. P. (Org.). Justiça Nacional, Justiça Europeia: a jurisprudência do Tribunal de Justiça da União Europeia. Coimbra: Almedina, 2011. p. 17-35.

SANDULLI, Irene. La responsabilità dello Stato-Amministrazione per violazione del diritto comunitario, fra istanze di certezza giuridica e tutela del principio dell'affidamento, Università degli studi di Roma 'Tor Vergata', Facolta' di Giurisprudenza, dottorato di ricerca in Diritto Pubblico, XXI Ciclo, 2008/2009. Disponível em: <http://dspace.uniroma2.it/dspace/bitstream/2108/1032/1/ Tesi+Irene+Sandulli.pdf $>$. Acesso em: 27 maio 2013.

SARMIENTO, Daniel. Un paso más en la constitucionalización del tercer pilar de la Unión Europea: la sentencia Maria Pupino y el efecto directo de las decisiones marco. Revista Electrónica de Estudios Internacionales, diciembre 2005, n. 10 Disponível em: < http://www.reei.org/index. php/revista/num10/archivos/D.Sarmiento(reeil0).pdf>. Acesso em: 24 maio 2013.

SCHIATTI, Daniela. Quale primato del diritto comunitario in ambito penale? Rivista di Diritto Internazionale Privato e Processuale, aprile-giugno 2008, anno XLIV, n. 2, p. 479-504.

SILVA, Karine de Souza. El cumplimiento del Derecho Comunitario por los Estados Miembros de la Unión Europea: alcances y limítes de la acción por incumplimiento. Jean Monnet/Robert Schuman Paper Series, october 2009, v. 9, n. 9. Disponível em: <http://aei.pitt.edu/14997/1/ SilvaSpanLawLong09Edi.pdf $>$. Acesso em: 24 maio 2013.

SOARES, António Goucha. Direito Comunitário: relatório sobre o programa, os conteúdos e os métodos do ensino da disciplina. Socius Working Papers, 2001, n. 5. Disponível em: <http:// pascal.iseg.utl.pt/ socius/publicacoes/wp/wp501.pdf>. Acesso em: 26 maio 2013. 
TORRES GAZORLA, María Isabel: La normativa comunitaria en materia turística y su aplicación por el Tribunal de Justicia Comunitario. Revista Andaluza de Derecho del Turismo, junio 2010, n. 4, p. 11-46.

UGARTEMENDÍA, Juan Ignacio; SARMIENTO, Daniel. La protección de los derechos fundamentales del ciudadano europeo en tránsito: ¿cuestión interna o comunitaria? InDret: Revista para el Análisis del Derecho, enero 2008, n. 1. Disponível em: <http://www.indret.com/pdf/498_ es.pdf>. Acesso em: 24 maio 2013.

VILAÇA, José Luís da Cruz. A propósito dos efeitos das directivas na ordem jurídica dos Estados-membros. Cadernos de Justiça Administrativa, nov.-dez. 2001, n. 30, p. 3-19.

WOHLFAHRT, Christian. Veränderungen des Lissabon-Vertrages im Hinblick auf die Doktrin der unmittelbaren Wirkung. Zeitschrift für ausländisches öffentliches Recht und Völkerrecht, 2010, v. 70, p. 523-545. Disponível em: < http://www.zaoerv.de/70_2010/70_2010_3_a_523_546.pdf>. Acesso em: 26 maio 2013.

ZAMORANO-GUZMÁN, Cristian. La gobernanza de la Unión Europea: principio de primacía, efecto directo y traumatismo fundador. Revista de Derecho (Pontificia Universidad Católica de Valparaíso), 2008, n. XXXI, p. 471-490. Disponível em: <http://www.scielo.cl/pdf/rdpucv/n31/ a13.pdf>. Acesso em: 23 maio 2013.

ZANGHİ, Claudio. Istituzioni di diritto dell'Unione Europea: verso una Costituzione Europea. 4. ed., Torino: Giappichelli, 2003. 